\title{
Embedded System Prototype to Fight Covid-19 Pandemic Contamination with Less Cost
}

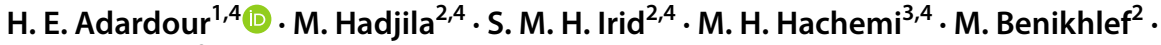 \\ I. Benotmane ${ }^{2}$
}

Accepted: 22 March 2021 / Published online: 9 April 2021

(c) The Author(s), under exclusive licence to Springer Science+Business Media, LLC, part of Springer Nature 2021

\begin{abstract}
In the shadow of the coronavirus (Covid-19) pandemic, the sterilization has become a major necessity for humans to avoid exponential Infection. In order to avoid touching contaminated surfaces, we develop an embedded system prototype, which allows the bottle or any other medium to pour the sterilization product without touching it. The human hands are detected using two sensors HC-SR04 and LM35. To overcome the stability problem due to the problem of sensor noise and enhance the system performance a Kalman filter algorithm is implemented to ensure stable hands detection. The efficiency of the prototype mounted on an Arduino board is checked. After the completion of the prototype, a comprehensive cost analysis is conducted.
\end{abstract}

Keywords Covid-19 $\cdot$ Kalman filter $\cdot$ Sterilization bottle $\cdot$ Arduino

H. E. Adardour

h.adardour@univ-chlef.dz

M. Hadjila

mhadjila_2002@yahoo.fr

S. M. H. Irid

sidimohammedhadj.irid@univ-tlemcen.dz

M. H. Hachemi

hicham.hachemi@univ-usto.dz

M. Benikhlef

m.benikhlef.univ.tlemcen@gmail.com

I. Benotmane

i.benotmane.univ.tlemcen@gmail.com

1 Department of Electronics, Faculty of Technology, University Hassiba Benbouali, Chlef, Algeria

2 Department of Telecommunications, Faculty of Technology, University Abou Bakr Belkaid, Tlemcen, Algeria

3 Department of Electronics, Faculty of Electrical Engineering, University of Science and Technology of Oran, Mohammed Boudiaf (USTO-MB), Oran, Algeria

4 STIC Laboratory, Faculty of Technology, University Abou Bakr Belkaid, Tlemcen, Algeria 


\section{Introduction}

COVID-19 (or coronavirus 2019 disease) is an infectious disease caused by the severe acute respiratory syndrome coronavirus 2 (or SARS-CoV-2), previously referred to as the new coronavirus 2019 (or 2019-nCoV), a type of coronavirus. The initial infections were observed in Wuhan, China, at the end of December 2019 before propagating around the world. The current outbreak was registered as a pandemic on 11 March 2020 [1, 2].

Many scientific research projects are underway, whether in medicine, pharmacy or technology. As far as medicine is concerned, the diagnosis of the coronavirus in the human body is extremely intricate and this is due to its strength and interaction which leads to its massive propagation in the human environment. As a result, the World Health Organization (or WHO) has insisted that all humanity should remain confined to its homes and not take to the streets to contain and eliminate this dangerous virus.

In the pharmaceutical field, they have found drugs that help decipher the virus, such as hydroxychloroquine and azithromycin, but they have not reached the limit, as some researchers think that the corona virus could return. For that, the optimal solution is a vaccine that prevents it from spreading completely.

In the technological field, we have observed that researchers work hard to engineer artificial respirators because these are very important for people infected with coronaviruses, which help them to breathe as the corona virus destroys lungs. In addition to this invention, they have manufactured devices to measure human temperature, which depends on infrared radiation to identify the infected persons with coronaviruses [3-7].

Everyone is aware of the danger of Covid-19 [8], and as we are an integral part of this world, we are investigating a new challenge in the technological field, the smarter sterilization bottles. This contribution favors reducing the propagation of virus.

Before presenting the proposed contribution in this paper, we are interested in explaining the importance of hand sterilization or hand washing or hand hygiene in health care and in the community.

However, the correct term of "sterilization" has more practical value than one might expect at first view [9]. On the other hand, if we ask the following question, what is the term "disinfection"? From [9], we found the answer to this question, the authors state that the disinfectant must be bactericidal, fungicidal, virucidal, etc. Nevertheless, the sterilization is a process after which no living organism can be detected.

For exact descriptions of the term "hand washing and hand hygiene", we present some related works in this context.

In [10], the authors report a scientific review of the effects of hand washing with soap on the risk of diarrhoea to estimate potential reductions in diarrhoeal deaths. However, the authors have declared that the hand washing is regarded as a key anti-infection practice. Furthermore, they noted that a lot of discussion exists on how to improve hand washing practices in health care facilities, but that little attention is focused on the importance of hand washing at home, particularly in developing countries. As a conclusion, they also mentioned that the modern methods of hand washing promotion have the potential to be effective and cost-effective on a large scale, because soap is broadly available even in poor developing countries' households, although, it is mainly applied for cleaning and washing clothes.

In [11], the authors discuss an interesting topic; concerning the cleanliness of surface environment and the risk of contamination when washing hands. However, the effective hand washing and including drying is important in infection control and to decrease 
skin-surface microbial counts. The authors in [11] examine a salient element, it is the environmental surface cleanliness, and in addition, they studied the contamination of hands during washing process. For this reason, they examined and analyzed the surfaces of hand washing stations that can be suffused with the bacteria that can be touched during hand washing. As solution for testing, the adenosine triphosphate (or ATP) used. According to certain findings, the authors noted that the contamination of hand washing surfaces can lead to the spread of microbial contamination in hospitals, and which can provide a pool of the microbial contamination, and finally, it can result in the contamination of hands during or after hand washing. In addition, they tested three areas of hand contact surfaces, namely: faucet handles, soap dispenser activation mechanisms and folded paper towel dispenser outlets. Finally, the obtained results indicate that the surfaces most sensitive to contamination are the faucet handles more than others.

Based on [12], the authors provide an overview about hand hygiene in health care and in the community, as well as hand drying and structural aspects which determine hand hygiene performance are also discussed. By definition, the authors report that the hand hygiene is the most effective measure to stop the spread of microorganisms that cause infections within the community and the health care environment. Due to the fact that the use of hand hygiene is considered unlikely to be successful in reducing infection, if it is seen as a sole measure to reduce infection whereas other infection control factors are absent, such as environmental hygiene. Therefore, the hand hygiene is part of an integrated infection control approach, and if one talks about the recommendations for hand hygiene all over the world, there is participation in this aspect tends to be very low, although the procedures involved in hand hygiene are not complicated [12]. In conclusion, the authors of [12] reached the conclusion that the health and community environment can be better if it is not based entirely on hand hygiene practices, but it must be accompanied with the environmentally clean surfaces. And in addition to these, the hand hygiene facilities must be also available and appropriate.

In the context of the aforementioned related works. The present paper aims to design and produce a prototype smarter sterilization bottle (or SSB) based on Arduino nano card with using some hardware components connected, and which is dedicated to the prevention of Covid-19 and resolves the issues raised by the authors in the above references, among them the cleanliness of surface environment for the hand hygiene facilities. Finally, we encourage hand sterilizing without contact with the sterilization bottle or the hand hygiene facilities in order to reduce the risk of contamination of hands during or after hand sterilizing. In the Fig. 1, we present the model of old sterilization bottle (see Fig. 1a) and the SSB which will be studied and examined in this work (see Fig. 1b).

However, Fig. 1b illustrates the principal part of SSB designing, which contains the sensors, the Arduino nano card, the DC water motor and the power supply.

In this work, an experimental study of SSB is based on the detection of human hands to be sterilized. The SSB works without any mechanical action on it, it operates by bringing the hands in front of the HC-SR04 ultrasonic sensor with priably adaptive distance. Moreover, the SSB is installed in an intermodal measurement room (or IMR) in order to obtain real results. The SSB use a hybrid system for running, which is based on two sensors at the same time, and are as follows: the LM35 temperature sensor and the HC-SR04 ultrasonic sensor. The Arduino nano card is employed for data acquisition.

As mentioned before, the SSB system is a hybrid system based on temperature measurement to estimate the detectable distance between the SSB and human hands to be sterilized. For more details see the theory of ultrasonic waves section. 


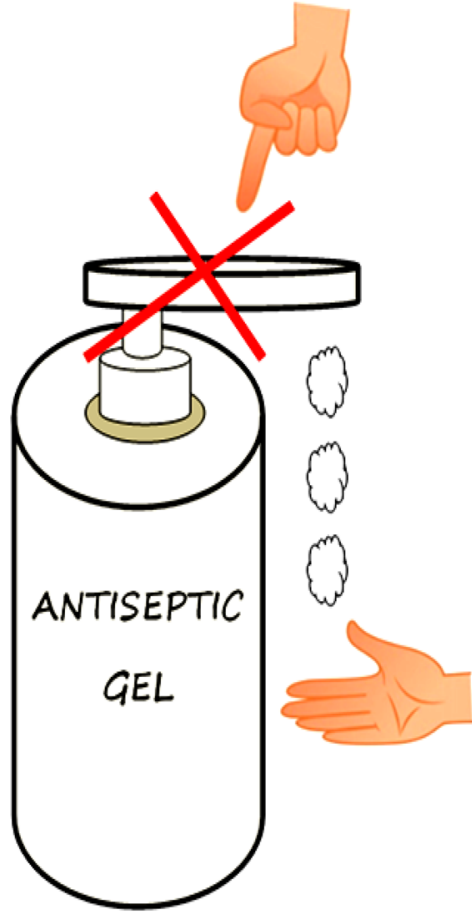

(a)

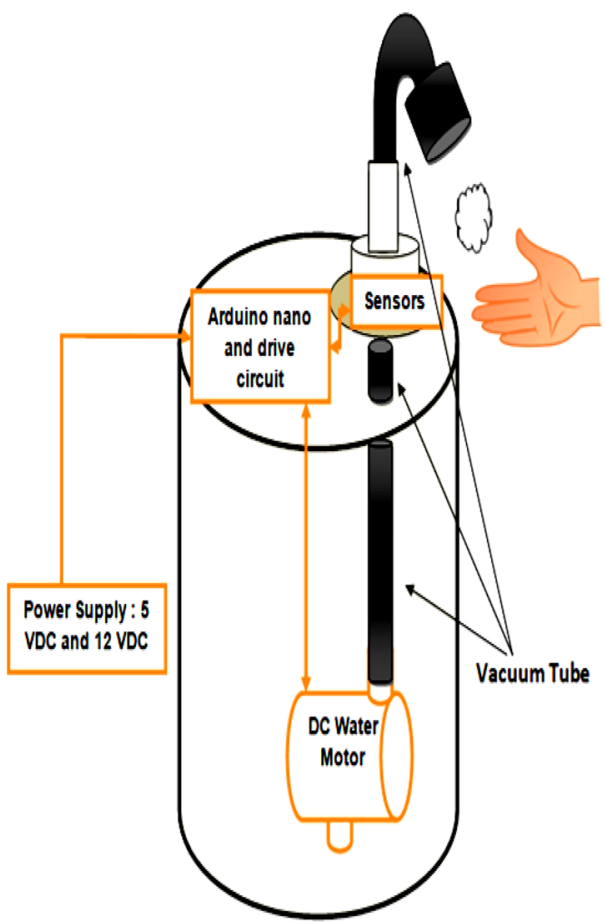

(b)

Fig. 1 a Old sterilization bottle and $\mathbf{b}$ smarter sterilization bottle

During the distance measurement between the human hands to be sterilized and the SSB, the sensors generate a noise, called the measurement noise, which can affect on the performance of proposed system. To do that, the Kalman Filter (or KF) is proposed and implemented to improve the stability of distance measurement. The test results obtained show the effectiveness of KF algorithm after the reduction of measurement noise from the sensors.

The test analysis is performed under the Arduino IDE environment. The most important thing in this work is the integration of KF in the proposed system in order to increase the accuracy measuring for detecting human hands to be sterilized. Finally, the used methodology to achieve better results is based on the conceptual diagram shown in Fig. 2.

The remainder of the article is organized as follows: The theory of ultrasonic waves is discussed in Sect. 2. In Sect. 3, the proposed prototype of SSB is introduced; and the KF algorithm is addressed in Sect. 4. In Sect. 5, the results and discussions are presented and the Sect. 6 concludes the research paper that is investigated. Finally, the Sect. 7 presents the short study of the future proposed low-cost prototype for the SSB.

\section{Theory of Ultrasonic Waves}

According to ultrasound wave theory, the speed of sound waves varies with the temperature of environment. Therefore, we proposed an intelligent hybrid system to measure the distance of human hands to be sterilized in front of the SSB, which are detected 


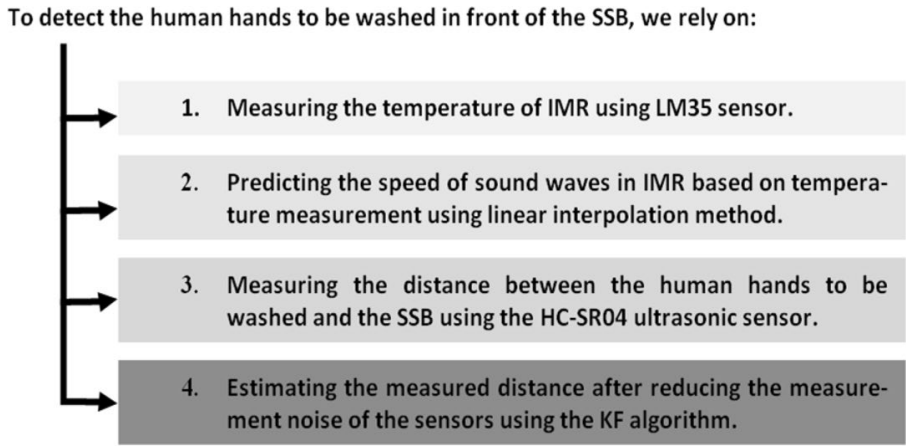

Fig. 2 Conceptual diagram of the proposed system

based on the temperature of environment in IMR. However, the ultrasonic signals are the mechanical force waves of frequencies that are higher than those audible to the human ear. In typical use, the frequency band is from $[20 \mathrm{kHz}$ to $1 \mathrm{GHz}]$. The latter covering a wide variety of applications. In fact, the frequency band from $[20 \mathrm{kHz}$ to $1 \mathrm{GHz}]$ can be subdivided into three major parts, which are defined as follows: the first frequency band from [20 kHz and $300 \mathrm{kHz}$ ] is primarily employed by sonar and animals for echolocation. The second frequency band from [800 kHz to $15 \mathrm{MHz}$ ] is devoted to non-destructive medical and industrial imaging applications. Finally, the third frequency band [12 $\mathrm{MHz}$ to $1 \mathrm{GHz}$ ] is reserved for acoustic microscopy applications [13].

As a definition, ultrasonic waves are mechanical vibrations representing a movement of the particles. They propagate in a fluid or solid medium, but cannot be propagated in a vacuum the same way as electromagnetic waves. Several modes of propagation can be observed depending on the nature of the medium. In addition, the ultrasonic waves, concentrated in the form of beams, will act on the material through which they are travelling. The amplitude of these waves decreases during the propagation because the bonds among atoms or molecules are not entirely elastic. A number of phenomena occur that result in their weakening:

- absorption in homogeneous mediums, when the ultrasonic wave propagates, it transfers part of its energy to the medium.

- reflections, refractions and scattering at environmental changes (acoustic interface) [14].

There are multiple systems that can produce ultrasound. Usually, a device that delivers ultrasound is often referred to as an ultrasonic transducer or ultrasonic converter. However, the transducer technology can be based on pneumatic generators. On the other hand, there are various systems that can generate ultrasound, electrodynamics (loudspeaker) or electrical. In the latter case, the properties of magnetostrictive or piezoelectric materials are applied to convert electrical energy into ultrasonic mechanical energy.

Presently, the most widely employed materials are piezoelectric materials. These materials are in the form of a disc or a ring on the faces of which two metalized electrodes are disposed. When a voltage is supplied to these two electrodes, the material expands or compresses according to the orientation of the voltage with respect to the polarization of the ceramic. Inversely, by applying a force to the material, the opposite 
effect will occur, and as a result, a voltage will appear across the electrodes to produce the ultrasonic energy.

The movement or vibration amplitudes of these ceramics are typically very small (about a few microns). To create interesting effects on the material, the vibration amplitude of the tool in contact with the medium must be many tens of microns. To obtain this result, it is generally stacked several ceramics one on top of the other, which will be held under pressure between two metallic masses. The selection of the material constituting these masses and the choice of their cross-section enables the vibration to be enhanced in the privileged direction (cutting plane). The transducers thus created develop a maximum movement at certain particular frequencies, which depend on the geometry of the transducer, itself; we call these frequencies the resonance frequencies. The use of these transducers is commonly limited to these particular frequencies. To produce an ultrasonic wave, the principle involves supplying the ultrasonic systems with an electrical voltage whose frequency is equal to their resonant frequency.

Today, ultrasonic sensors are the simplest way to detect ultrasonic obstacles. The transmitter and receiver are both integrated in a box. The ultrasound is directly reflected to the receiver by the obstacle to be detected. The majority of ultrasonic sensors are based on the principle to measure the path of sound between transmission and reception. The time taken for the echo to return is proportional to the distance between the ultrasonic sensor and the sensing obstacle [15].

\section{Proposed Prototype}

In this section, we explain the circuit of proposed prototype SSB shown in Fig. 1b. In this prototype circuit (see Fig. 3), four components are used: the DC water motor is used to pump the antiseptic gel up out of the SSB, the control circuit is used to receive the physical signals from the HC-SR04 ultrasonic sensor in order to energize the DC water motor, here, the HC-SR04 ultrasonic sensor is employed to follow the threshold distance in order to detect the human hands to be sterilized, and the power supply of 12 VDC is applied to supply the control circuit to drive the DC water motor. As we mentioned in previous paragraphs, the LM35 sensor is used to measure the temperature and this in order to predict the speed of sound waves for measuring the distance between the human hands and the SSB. The Arduino nano card is powered by 5 VDC [16].

However, the HC-SR04 ultrasonic sensor enables to sense the presence of the human hands in the sensor beam field, see Fig. 4. It is applied in various applications, such as: security systems and motion detectors [17]. It is available at low cost, and it is very simple to use. In addition, the ultrasonic module HC-SR04 has 4 pins, VCC, GND, echo and trigger. The VCC and GND pins of the sensor must be attached respectively to the $5 \mathrm{~V}$ and GND pins on the Arduino nano card and the echo and trig pins are respectively connected to 12 and 10 digital I/O pins on the Arduino nano card [16].

For producing the ultrasound, we must select a high trigger level of $10 \mu \mathrm{s}$ [17]. This will transmit an 8-cycle tone burst that will move at the speed of sound waves and be detected in the echo pin. The echo pin will provide the time in microseconds that the sound waves will move (see Fig. 5). On the other hand, Fig. 6 illustrates the circuit for controlling the DC water motor. When the HC-SR04 ultrasonic sensor detects the human hands to be sterilized, the DC water motor is powered by the proposed circuit of Fig. 6. However, the costly component of this prototype is the DC water motor, as 


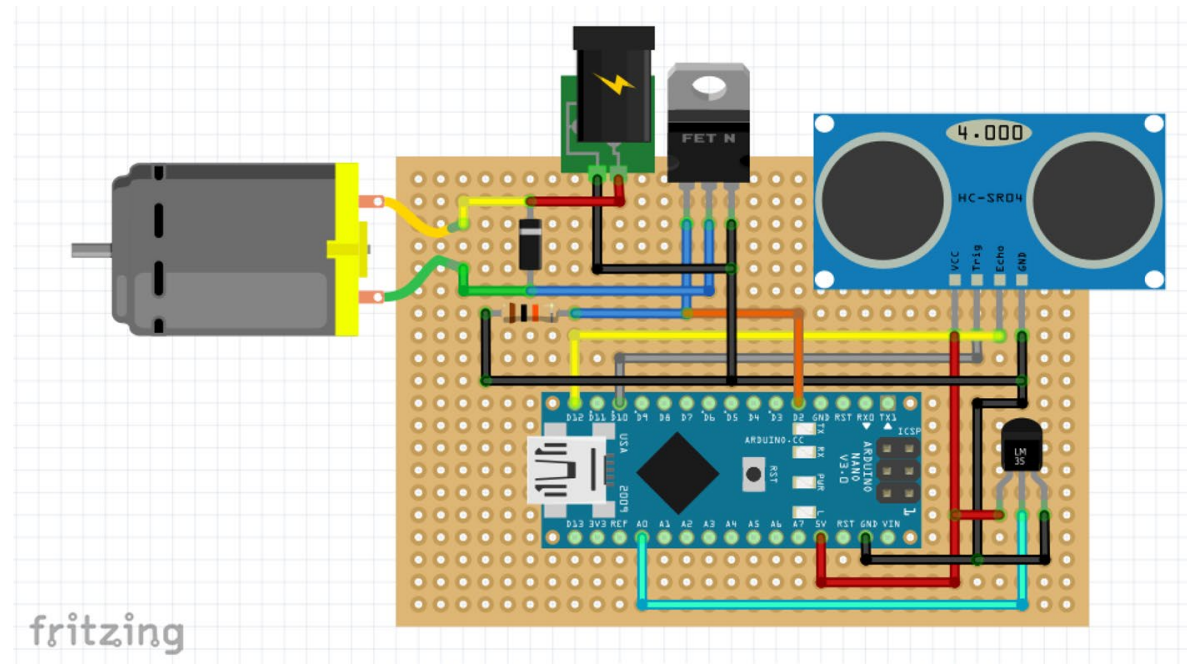

Fig. 3 Proposed prototype

Fig. 4 Human hands sensing by a HC-SR04 ultrasonic sensor
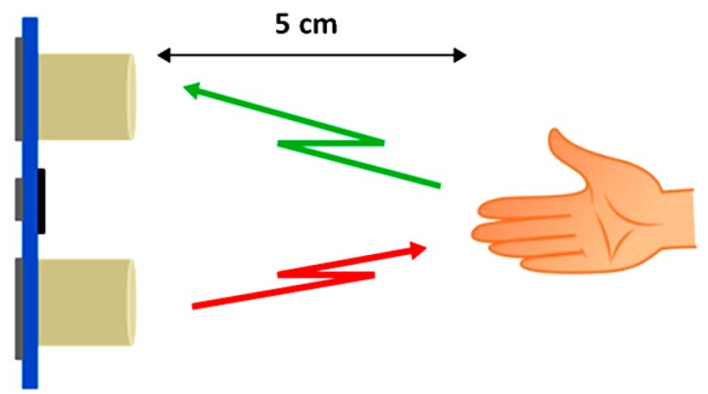

shown in the Fig. 3. Finally, the basic source code to run the proposed prototype of Fig. 3 is presented in Appendix 1 section.

\section{Kalman Filter Algorithm}

The Kalman filter is a mathematical method designed by Professor RUDOLF KALMAN in 1960. This filter was first used to solve trajectory tracking problems in preparation of the Apollo flights. It has become an essential algorithm for the trajectory processing in modern radar systems and other engineering applications [18-27]. In this paper, the application of KF plays an indispensable role, which aims to reduce the measurement noise of the used sensors in the proposed prototype, and through it, we can stabilize the operation of system in order to make it more efficient. 


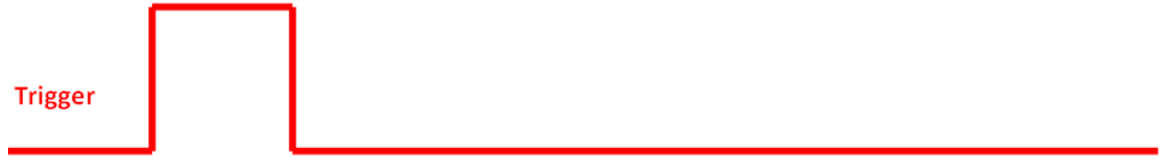

Fig. 5 Trigger versus echo

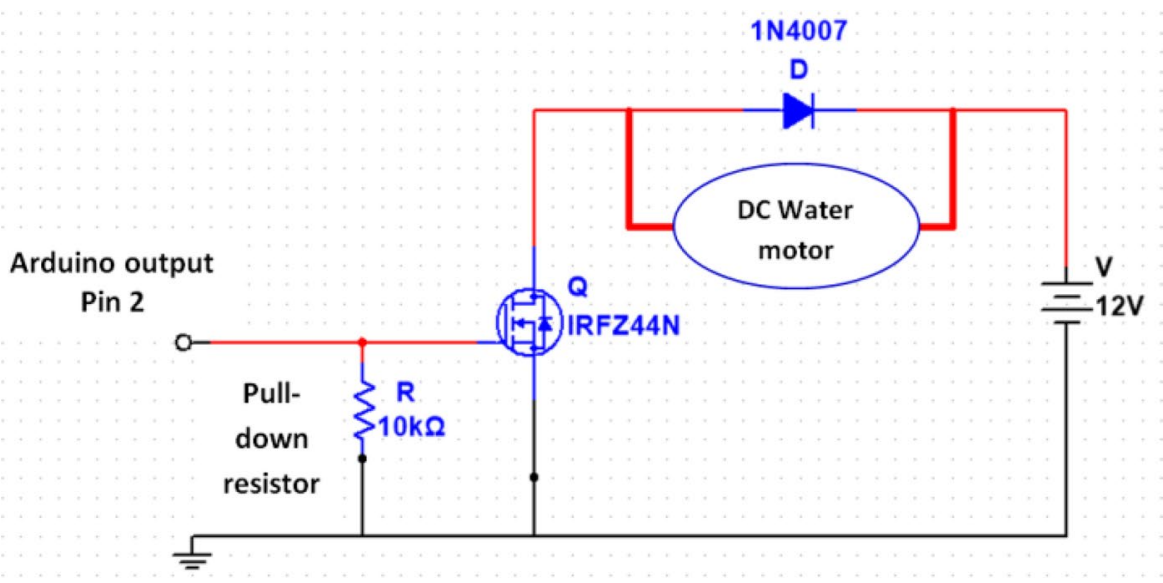

Fig. 6 Driving circuit for DC water motor

\subsection{Definition}

The Kalman Filter (KF) consists of a recursive filter, which employs a temporal filter approach. It enables to estimate the state (this state corresponds to the desired information) of a dynamic system based on a priori information on the state evolution (model) and real measurement. It is highly encouraged to employ this filter when the uncertainty on the processed acquisition data can be understood, as a random noise, which's the distribution, is known a priori. However, one of the great advantages of the KF algorithm, are as follows: the estimation error, is considered as an indicator of accuracy; and its algorithm has a recursive nature in time domain, and it disposes an optimal estimator in the least-squares meaning [18, 28-30]. 


\subsection{Application}

In this sub-section, we will discuss the application of KF for the proposed system. The principle of this filter is based on a state variable model with two equations, namely [18, 31-33]:

- the recursive equation of discrete random process modeling (state vector), it is also referred to as the state equation or transition equation.

- the observation equation (measurement vector) of process, it is also referred to as the measurement equation.

The KF algorithm wording is designed in discrete time form to estimate the state and measurement of dynamic model, which is described as follows:

$$
\left\{\begin{array}{l}
\mathrm{x}_{\mathrm{k}+1}=\mathrm{F}_{\mathrm{k}} \mathrm{x}_{\mathrm{k}}+\mathrm{B}_{\mathrm{k}} \mathrm{u}_{\mathrm{k}}+\mathrm{w}_{\mathrm{k}}, \mathrm{w}_{\mathrm{k}} \rightarrow N\left(0, \mathrm{Q}_{\mathrm{k}}^{\mathrm{w}}\right) \\
\mathrm{z}_{\mathrm{k}}=\mathrm{H}_{\mathrm{k}} \mathrm{x}_{\mathrm{k}}+\mathrm{v}_{\mathrm{k}}, \mathrm{v}_{\mathrm{k}} \rightarrow N\left(0, \mathrm{R}_{\mathrm{k}}^{\mathrm{v}}\right)
\end{array}\right.
$$

With $x_{k}$ : state vector at time $\mathrm{k}$ which incorporates the acquisition data to be estimated, $x_{k} \in \mathbb{R}^{n} ; F_{k}$ : transition matrix. It depicts the evolution of the state vector from time k-1 to time $\mathrm{k}, F_{k} \in \mathbb{R}^{n * m} ; B_{k}$ : command matrix at time $\mathrm{k}$; it depends of the system modeling, $B_{k} \in \mathbb{R}^{n * l} ; H_{k}$ : observation matrix (measurement). In fact, it is the link between system variables and measurements, $H_{k} \in \mathbb{R}^{m * n} ; u_{k}$ : vector representing the applied commands to the system at time $\mathrm{k}, u_{k} \in \mathbb{R}^{l} ; w_{k}$ : vector representing the noise modeling at time $\mathrm{k}$, it is related to the uncertainty in process model, $w_{k} \in \mathbb{R}^{n} ; Q_{k}^{w}$ : covariance matrix of the process noise at time $\mathrm{k} ; z_{k}$ : measurement vector at time $\mathrm{k}, z_{k} \in \mathbb{R}^{m} ; v_{k}$ : vector representing the measureent noise at time $\mathrm{k}, v_{k} \in \mathbb{R}^{m} ; R_{k}^{v}$ : covariance matrix of the measurement noise at time $\mathrm{k}$.

However, the KF algorithm is divided into two main phases, which go as follows: the prediction phase and the correction phase. In prediction phase, the used algorithm is checked according to the following equations:

$$
\begin{aligned}
& \hat{x}_{k}^{(+)}=F_{k-1} \hat{x}_{k-1}^{(-)}+B_{k-1} u_{k-1} \\
& P_{k}^{(+)}=F_{k-1} P_{k-1}^{(-)} F_{k-1}^{T}+Q_{k}^{w}
\end{aligned}
$$

where $\hat{x}_{k}^{(+)}$denotes the estimated current state (a priori) for the estimated previous state (a posteriori) $\hat{x}_{k}^{(-)}$and $P_{k}^{(+)}$indicates the estimated current error of covariance matrix, whereas $Q_{k}^{w}$ is the covariance matrix of process noise. On the other hand, in correction phase, the used algorithm is examined by other equations, in the following manner:

$$
\begin{gathered}
K_{k}=P_{k}^{(+)} H_{k}^{T}\left(H_{k} P_{k}^{(+)} H_{k}^{T}+R_{k}^{v}\right)^{-1} \\
\hat{x}_{k}=\hat{x}_{k}^{(+)}+K_{k}\left(z_{k}-H_{k} \hat{x}_{k}^{(+)}\right) \\
P_{k}=\left(I-K H_{k}\right) P_{k}^{(+)}
\end{gathered}
$$




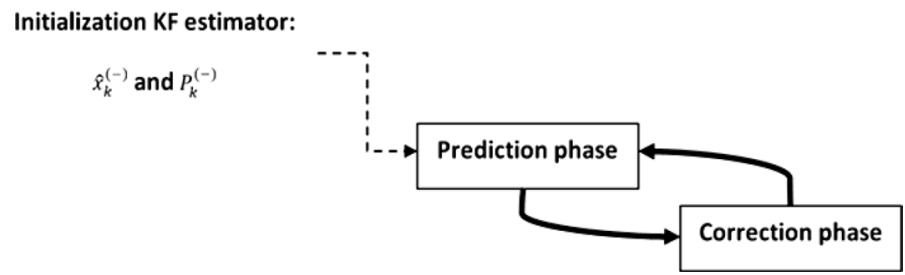

Fig. 7 Conceptual diagram of Kalman Filter estimator

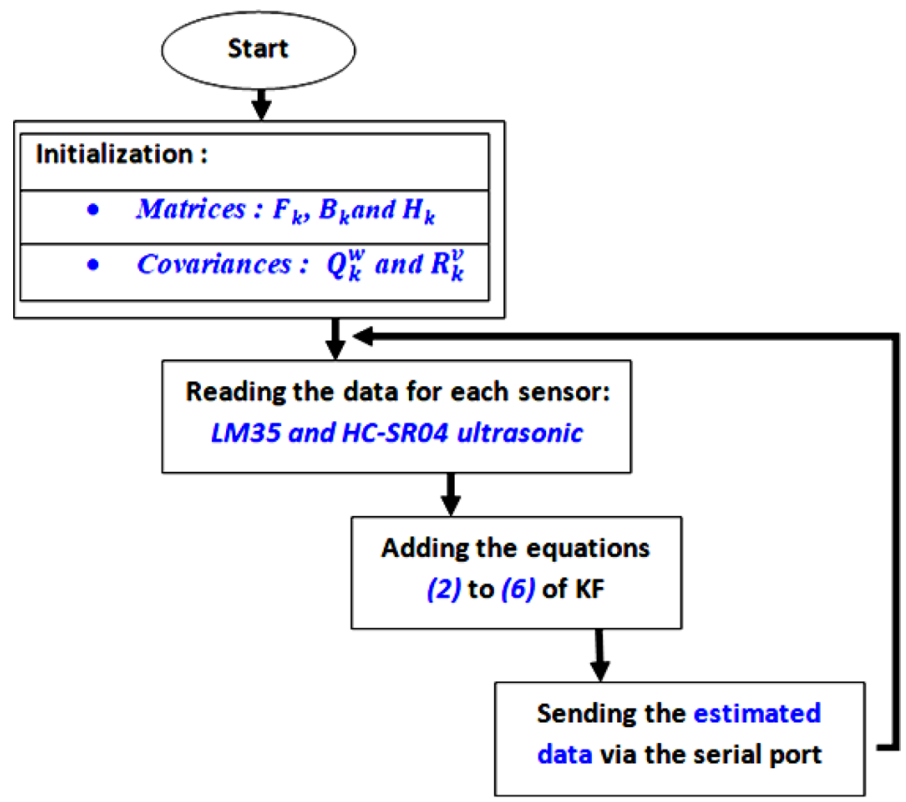

Fig. 8 Flowchart of final source code

where $K_{k}$ is the Kalman gain which serves to reduce the error of covariance matrix (a posteriori) $P_{k}$, and $R_{k}^{v}$ is the covariance matrix of measurement noise.

According to the above Eqs. (2)-(6), the concept process of KF algorithm shows that the prediction and correction process occurs in a way continuously (called the correction cycle see Fig. 7) in order to generate the estimated measurement values. Due to the correction cycle, the measurement noise which appears in the LM35 sensor and HC-SR04 ultrasonic sensor, can be removed.

Finally, the design of KF algorithm for the two sensors (LM35 and HC-SR04 ultrasonic), which we used for estimating the temperature, the speed of sound waves and the measured distance between the human hands and the SSB, are based on the above Eqs. (2)-(6), where these equations are implemented as a programming language on the IDE Arduino. More particularly, the flowchart of programming design in Fig. 8 explains in detail the famous source code to be executed on the Arduino nano card for the proposed system in this paper. 


\section{Results and Discussion}

In this section, we present and discuss the obtained results of the methodology proposed in Fig. 2. However, through this proposed methodology, we will design a prototype of SSB with a higher performance. At the end of this section, we will present the final prototype of SSB.

\subsection{Measuring the Temperature of Environment in Which Ultrasound is Spread}

In this sub-section, we will present the first step of conceptual diagram depicted in Fig. 2. The objective of this step is to measure the temperature of the environment in which the ultrasound is propagated using a LM35 temperature sensor in order to predict the speed of sound waves with the use of linear interpolation method. However, Fig. 9 illustrates the proposed diagram that we used for monitoring the temperature in IMR where we will install the SSB. In Fig. 9, we rely on two platforms, namely: Arduino and MATLAB. The Arduino platform has become so versatile that it has developed a lot of software to support many different applications. It has also developed MATLAB support software, which provides real-time data acquisition and plotting directly from the MATLAB command window from Arduino. This real-time data can be used to predict the speed of propagated sound waves in IMR based on the behavior of LM35 temperature sensor.

This part focuses mainly on automation and data acquisition in real-time. The acquisition data is achieved through the MATLAB platform, simply by programming, without using the toolbox or the Simulink platform, which would make the use easier and would constitute a less expensive way to acquire real-time data. On the other hand, the automation is obtained using an Arduino nano card and the MATLAB platform, by connecting the "LM35" temperature sensor to the Arduino nano card. The LM35 temperature sensor is preferred for this job, as instead of having to use a thermistor, the LM35 allows us to measure the temperature more accurately. The circuit of this part is very easy and is depicted in "Appendix 2" section.

In this research, a real-time graph of the temperature sensor was obtained, as shown in Fig. 10. On the graph, the measured temperature is plotted in orange and the temperature estimated using the $\mathrm{KF}$ is plotted in light green. The temperature is taken on the $\mathrm{Y}$-axis and its unit is the degree Celsius $\left({ }^{\circ} \mathrm{C}\right)$. From the obtained results in Fig. 10, one can clearly see that the use of KF to estimate the measured temperature provided more stable values in terms of estimation, and in addition, the estimated values are closer to the actual values. As an example, the measured average temperature value is

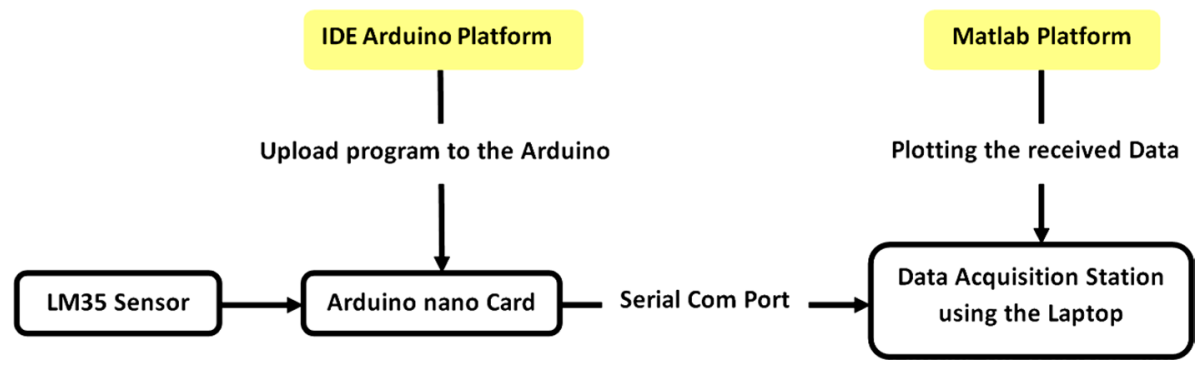

Fig. 9 Diagram for the acquisition of temperature data via a LM35 sensor 


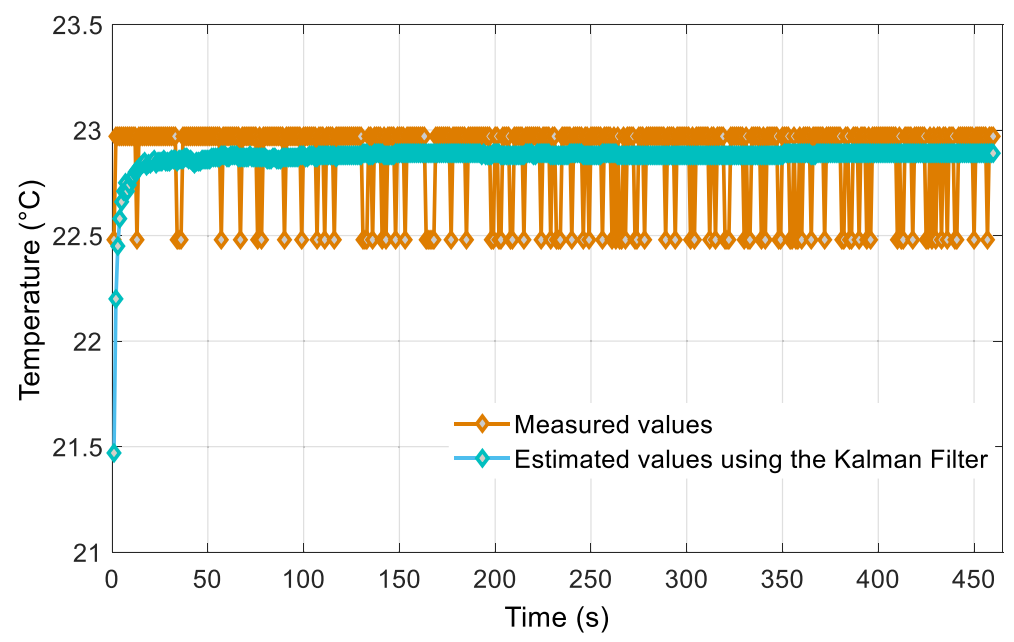

Fig. 10 Measured and estimated temperature values using a LM35 sensor

$22.8667{ }^{\circ} \mathrm{C}$, whereas the estimated average temperature value is $22.8720{ }^{\circ} \mathrm{C}$. Based on the results obtained from the test, it was noted that the KF algorithm reduces the measurement noise and has a better performance depending on the covariance value of process noise which was selected at $\mathrm{Q}=10^{-9}$. As conclusion, the estimated average error of temperature is equal to $0.0053{ }^{\circ} \mathrm{C}$.

Based on the estimated temperature of IMR in which we are hoping to implement the prototype of SSB (see Figs. 1, 3), we can predict the speed of sound waves in this IMR using the linear interpolation method. The predictive values will be computed on the basis of Table $1[34,35]$.

Figure 11 illustrates the expected results of the speed of sound waves in IMR. One can clearly notice that the values of the speed of sound waves follow the same path compared to the results of previously measured temperature, because theoretically and practically the speed of sound waves is relatively related to the temperature of the environment where the ultrasonic waves are present. As an example, the measured average value of the speed of sound waves is $344.9557 \mathrm{~m} / \mathrm{s}$, whereas the estimated average value of the speed of sound waves is $344.9589 \mathrm{~m} / \mathrm{s}$. As conclusion, the estimated average error of the speed of sound waves is equal to $0.0032 \mathrm{~m} / \mathrm{s}$.

Table 1 Speed of sound wave according to the temperature in the air

\begin{tabular}{ll}
\hline $\mathrm{T}\left({ }^{\circ} \mathrm{C}\right)$ & $\mathrm{c}\left(\mathrm{m} \mathrm{s}^{-1}\right)$ \\
\hline-10 & 325.4 \\
-5 & 328.5 \\
0 & 331.5 \\
+5 & 334.5 \\
+10 & 337.5 \\
+15 & 340.5 \\
+20 & 343.4 \\
+25 & 346.3 \\
+30 & 349.2 \\
\hline
\end{tabular}




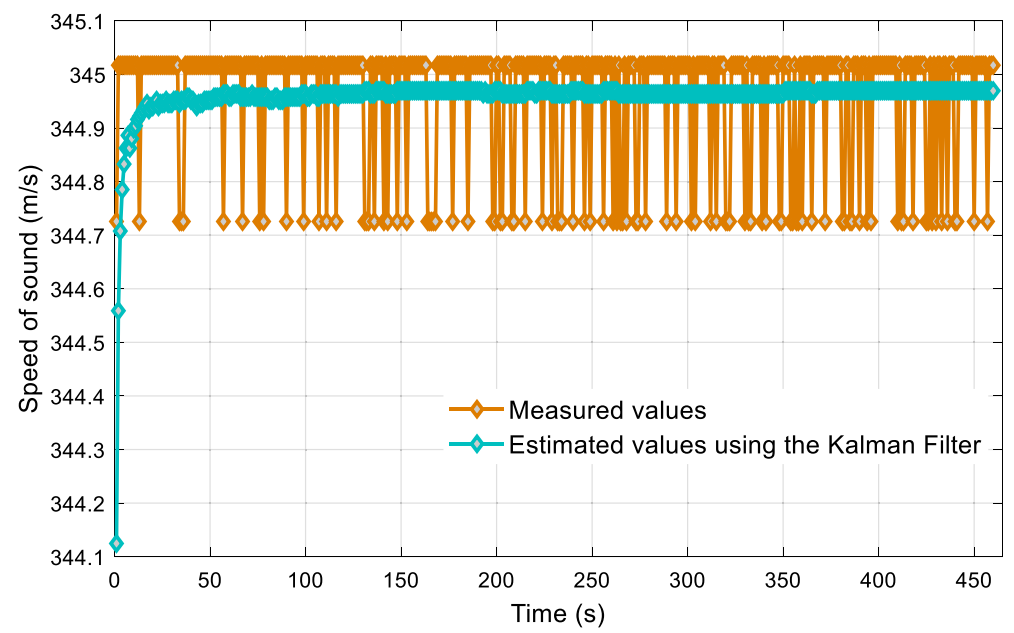

Fig. 11 Measured and estimated values of the speed of sound waves using a LM35 sensor

\subsection{Measuring the Speed of Sound Waves with an Ultrasound Sensor}

After predicting the speed of sound waves in a very specific environment (or IMR) using the LM35 sensor in the first scenario (see Fig. 9), we will measure in the second scenario, the speed of sound waves using an ultrasonic sensor, namely the HC-SR04 ultrasonic sensor. This sensor measures the time it takes to ping an ultrasound to go out, bounce off a target and come back. The time that the ping takes to get back to the sensor depends on the speed of sound waves and the distance to the target, here, the human hands to be sterilized are the obstacle. In addition, this sensor works in the same way as a bat that uses treble tones to navigate in the dark. This is also the same principle used in underwater sonar. The circuit for this part is very simple and is depicted in "Appendix 2" section.

However, the Fig. 12 shows the proposed diagram that we used to measure the speed of sound waves that allowed us to detect the human hands at $15 \mathrm{~cm}$ in the same IMR where we measured and estimated the temperature. In addition, we always rely on both platforms, namely Arduino and Matlab.

In this scenario, the test was performed to study measurement and estimation performance under steady state conditions. The test was carried out by placing the sensor

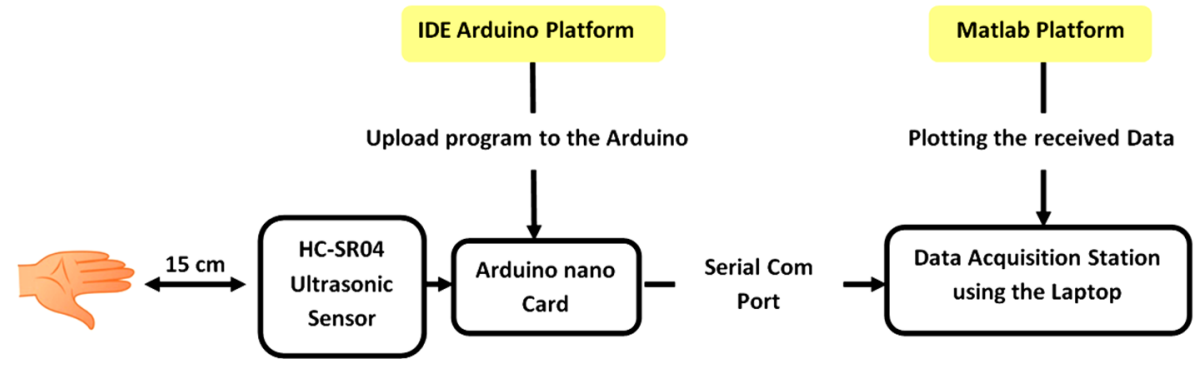

Fig. 12 Diagram for the acquisition data of the speed of sound waves via a HC-SR04 ultrasonic sensor 
in front of the human hands to be sterilized at a distance of $15 \mathrm{~cm}$. The test results are shown in Fig. 13.

The measured values of the speed of sound waves in orange and the estimated values in light green using the KF are shown in Fig. 13. As expected, the measured and estimated values for detecting the human hands to be sterilized at a distance of $15 \mathrm{~cm}$ are practically identical because the measurement noise has been attenuated by the KF. Obviously, the estimated values have a much smoother curve and a smaller range than the measured values. One can also clearly see that the transitional regime for the estimated values is rapidly evolving towards a stable state. As an example, the measured average value of the speed of sound waves is $345.4064 \mathrm{~m} / \mathrm{s}$, whereas the estimated average value of the speed of sound waves is $345.1625 \mathrm{~m} / \mathrm{s}$. On the basis of the test results obtained, it was established that the application of KF algorithm with the ultrasonic sensor also reduces the measurement noise and has a better performance according to the same covariance value of process noise which has been set at $\mathrm{Q}=10^{-9}$.

As conclusion, the estimated average error of the speed of sound waves is equal to $0.2439 \mathrm{~m} / \mathrm{s}$. As a final conclusion of the two previous scenarios concerning the measurement of the speed of sound waves in the air, we found that we can employ a temperature sensor with an ultrasonic sensor in order to detect and measure the distance of the human hands in a congested environment (or IMR), and this, according to the comparative results that have been presented in Figs. 11 and 13. In the following scenario, we will use a hybrid system comprising both the LM35 and HC-SR04 ultrasonic sensors.

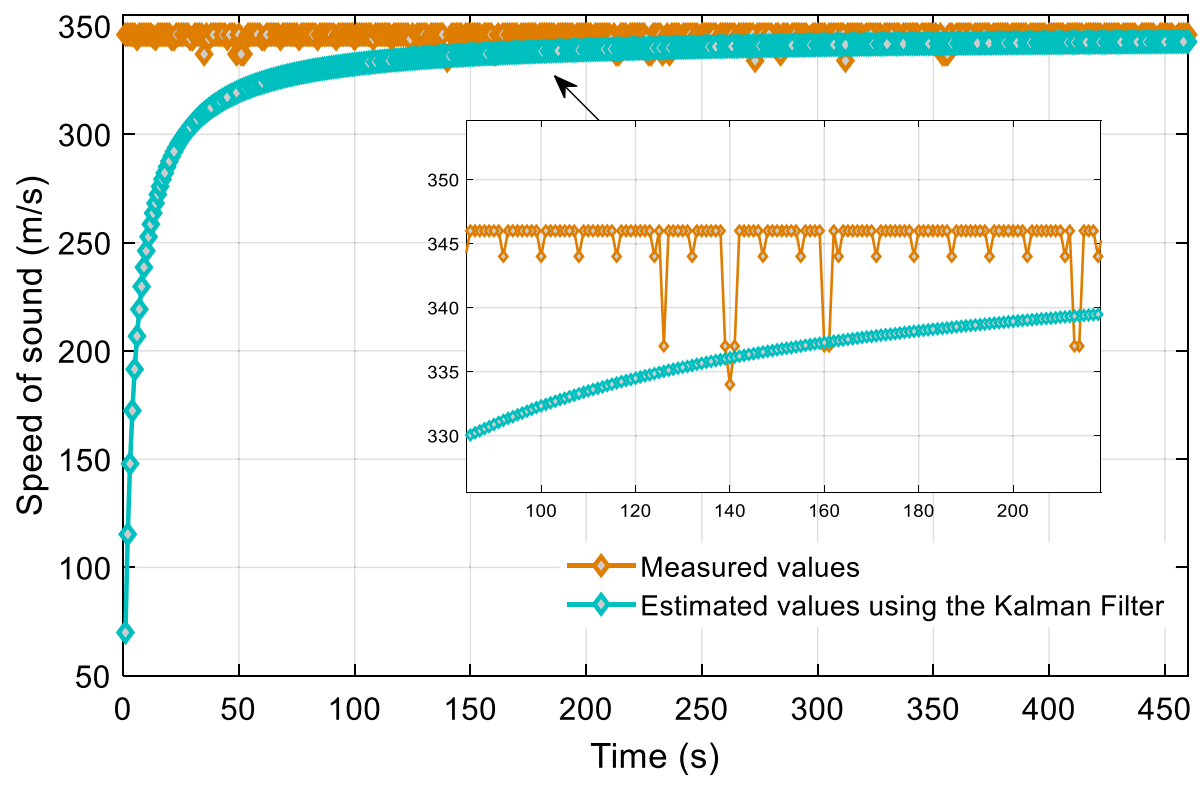

Fig. 13 Measured and estimated values of the speed of sound waves using a HC-SR04 ultrasonic sensor 


\subsection{Estimating the Distance of a Target Using a Hybrid System}

This sub-section focuses on the automatic calibration of hybrid system to react with the influence of temperature (see Fig. 14) in order to estimate the distance between the human hands and the SSB at $5 \mathrm{~cm}$ in the same IMR without fixing the speed of sound waves. The speed of sound waves will be computed and adjusted according to the LM35 sensor. The circuit of hybrid system for this part is very simple and is depicted in "Appendix 2". Moreover, Fig. 14 illustrates the proposed diagram that we used. In addition, we always rely on both Arduino and MATLAB platforms.

In this scenario, the test was performed to study and evaluate the performance of hybrid system whose purpose is to estimate the distance between the human hands to be sterilized and the SSB. For that, the HC-SR04 ultrasonic sensor is placed at the SSB and the human hands to be sterilized are fixed in front of SSB with a distance of $5 \mathrm{~cm}$ (see Figs. 1, 4 and 14). In addition, the use of LM35 sensor focuses to predict the speed of sound waves that will be selected to detect the human hands at $5 \mathrm{~cm}$ exactly. Finally, the test results of this scenario are shown in Fig. 15. In the previous scenario, we selected the covariance value of process noise to $\mathrm{Q}=10^{-9}$. In the current scenario, we vary the covariance value of process noise at $\mathrm{Q}=10^{-1}, \mathrm{Q}=10^{-3}, \mathrm{Q}=10^{-6}$ and $\mathrm{Q}=10^{-9}$, in order to observe their influence on the response time of HC-SR04 ultrasonic sensor when the distance between the human hands and the SSB changes. From the obtained test results for the estimated distance at $5 \mathrm{~cm}$, it appeared that the response time of hybrid system performance using the KF was different for each the covariance value of process noise tested. As an example, the covariance value of process noise $\mathrm{Q}=10^{-1}$, produces a faster response time of $4.56 \mathrm{~s}$, whereas the covariance value of process noise $\mathrm{Q}=10^{-9}$ produces a slower response time of $423.6 \mathrm{~s}$.

Thus, one can conclude that if the covariance value of the selected Q process noise is smaller, the response time of HC-SR04 ultrasonic sensor is slower and vice versa (see Fig. 16), as proved in [31, 32]. In our work, we wanted to select the covariance value of process noise at $\mathrm{Q}=10^{-1}$, as this was very helpful for our proposed prototype.

we also found that the estimated average error is smaller when the covariance value of process noise is larger (see Fig. 17). As an example, the estimated average errors for each covariance value of the process noise are respectively: $5.6 \times 10^{-3} \mathrm{~cm}\left(\mathrm{Q}=10^{-1}\right)$, $1.58 \times 10^{-2} \mathrm{~cm}\left(\mathrm{Q}=10^{-3}\right), 3.07 \times 10^{-2} \mathrm{~cm}\left(\mathrm{Q}=10^{-6}\right)$ and $3.37 \times 10^{-2} \mathrm{~cm}\left(\mathrm{Q}=10^{-9}\right)$.

In the end of this scenario, we also tested the performance of hybrid system with varying distances between the human hands and the SSB, namely: $5 \mathrm{~cm}, 6 \mathrm{~cm}$, and $7 \mathrm{~cm}$ on the

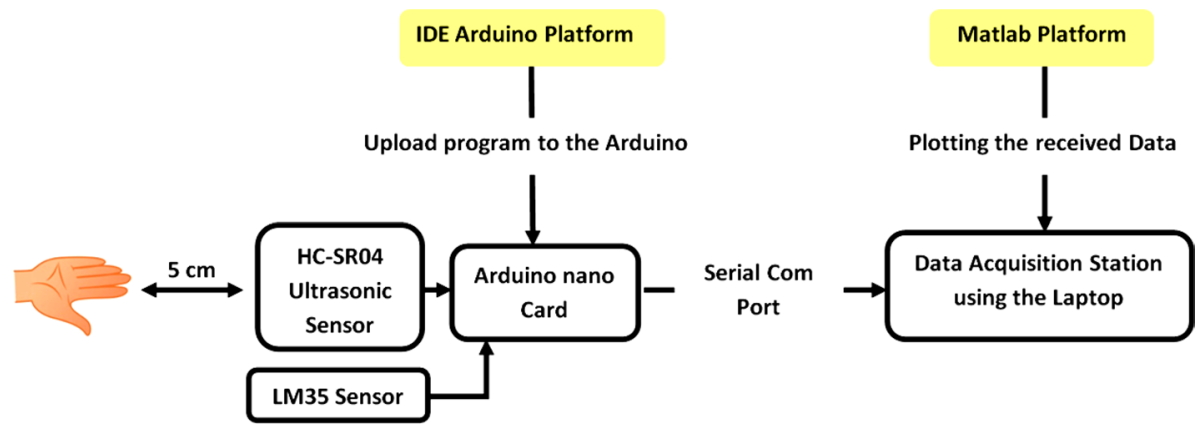

Fig. 14 Data acquisition diagram for a hybrid system 


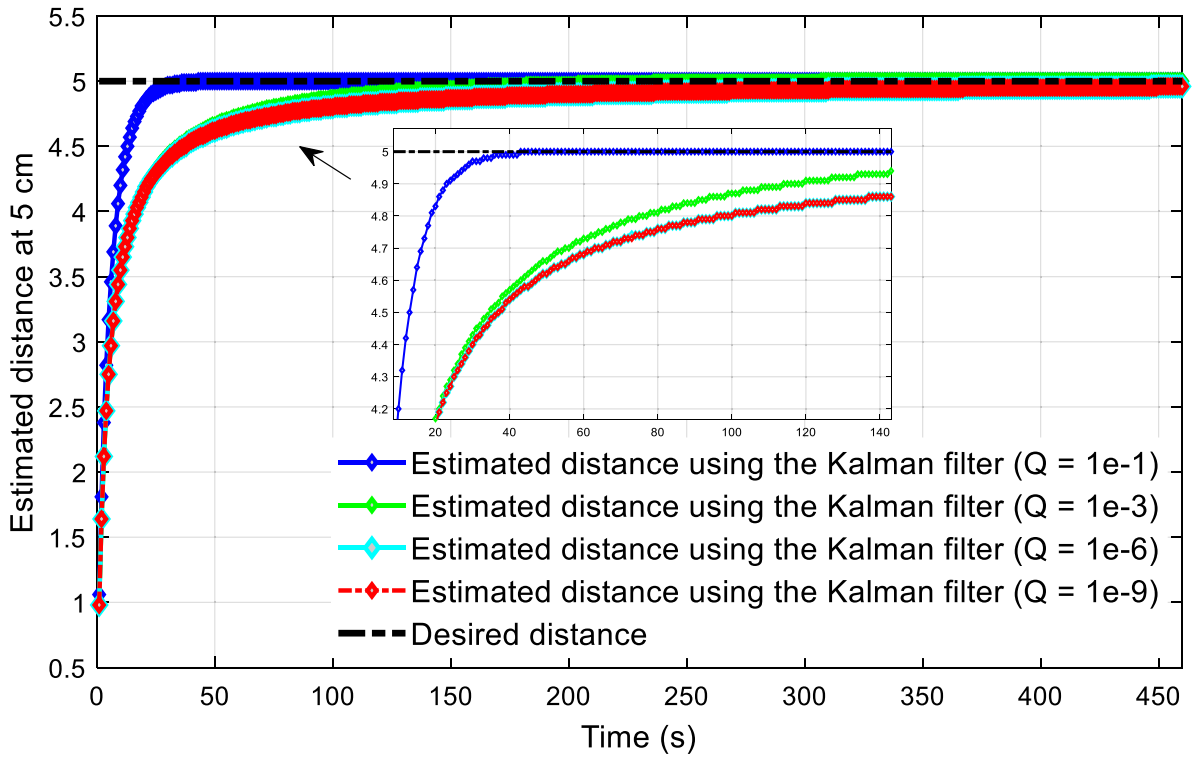

Fig. 15 Desired and estimated values of distances using a LM35 sensor and a HC-SR04 ultrasonic sensor

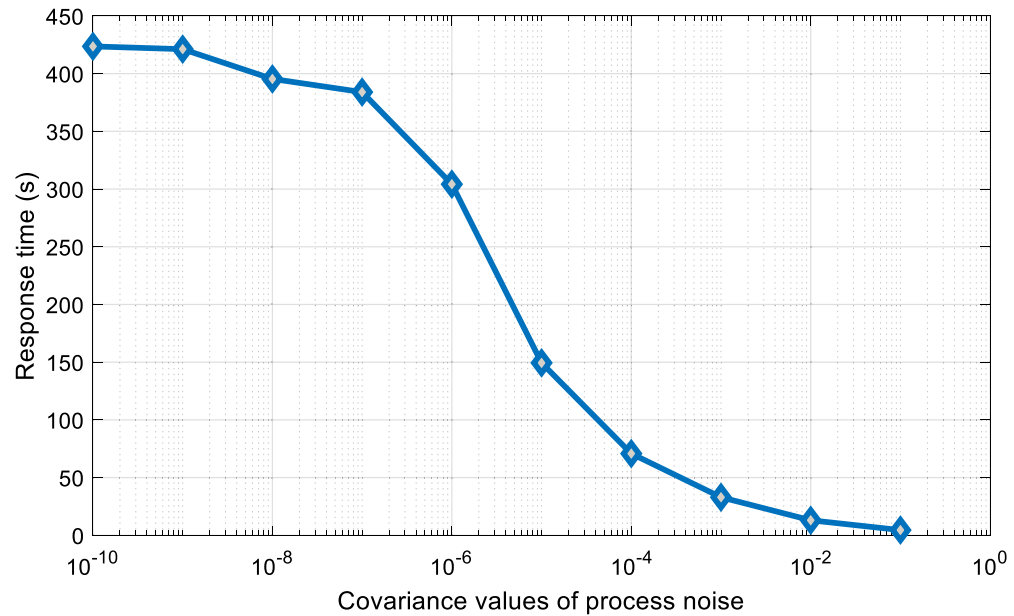

Fig. 16 Response time versus covariance value of the process noise

$\mathrm{X}$ axis, for the covariance value of process noise $\mathrm{Q}=10^{-1}$ (see Fig. 18), and this to validate our concept of this contribution when the threshold distance between the human hands and the SSB is changed in order to power the DC water motor for the pumping antiseptic gel.

\subsection{Validation of the Proposed Prototype}

In this sub-section, we present the final prototype of our contribution in Fig. 19. In addition, one can clearly see in Fig. 20 the realization of essential parts in this work. 


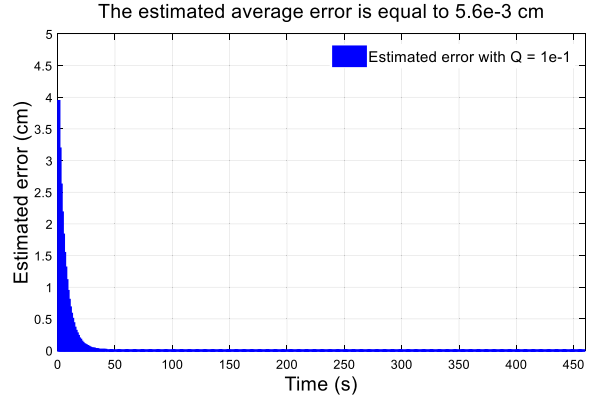

(a)

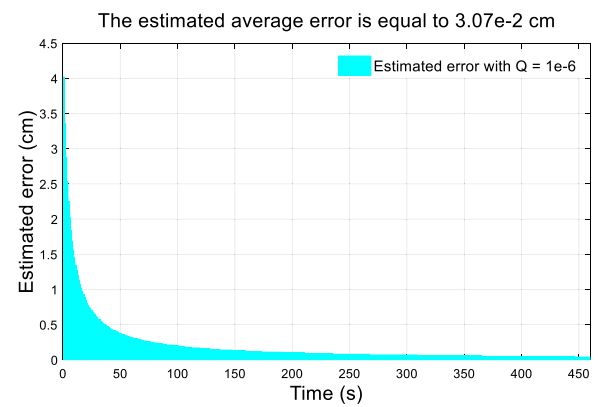

(c)

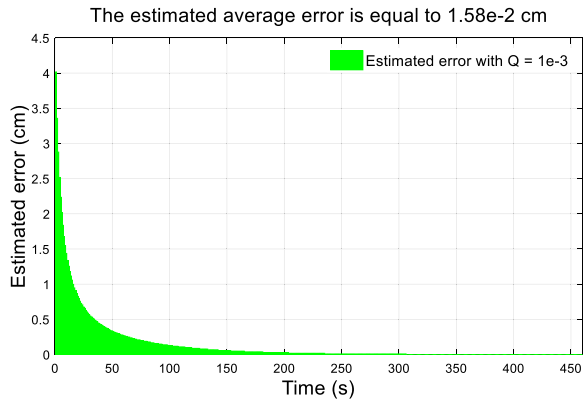

(b)

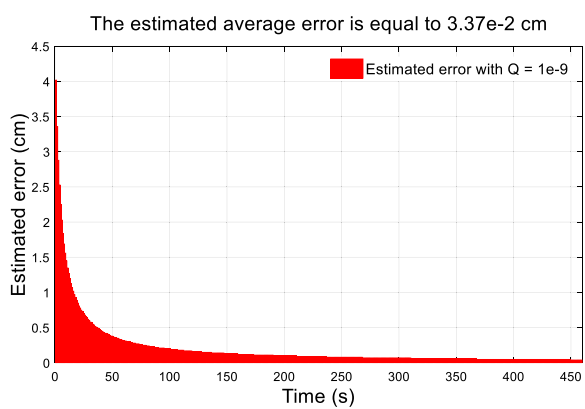

(d)

Fig. 17 Estimated error of distance for different covariance value of the process noise

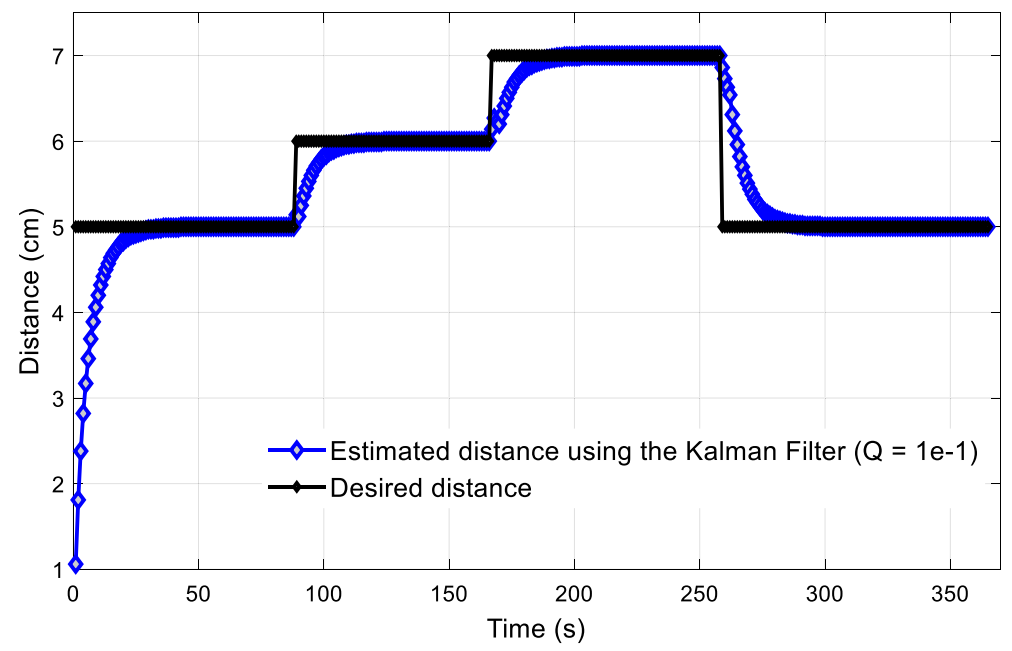

Fig. 18 Different distance values estimated using a LM35 sensor and a HC-SR04 ultrasonic sensor

Finally, the Fig. 21 shows some results obtained on the simulation of our prototype when the human hands are close to the SSB, such as: the measured temperature in IMR, the predicted speed of sound waves employing to measure and estimate the distance between the 


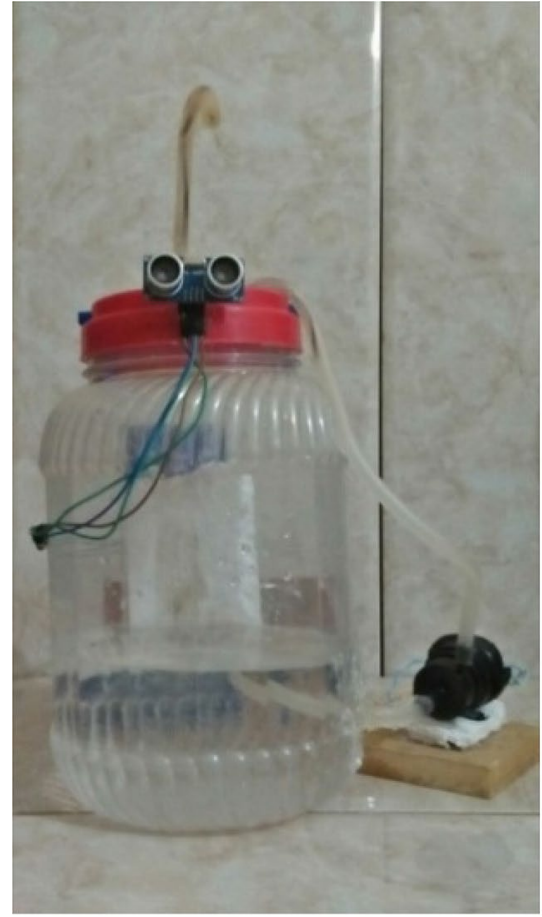

(a)

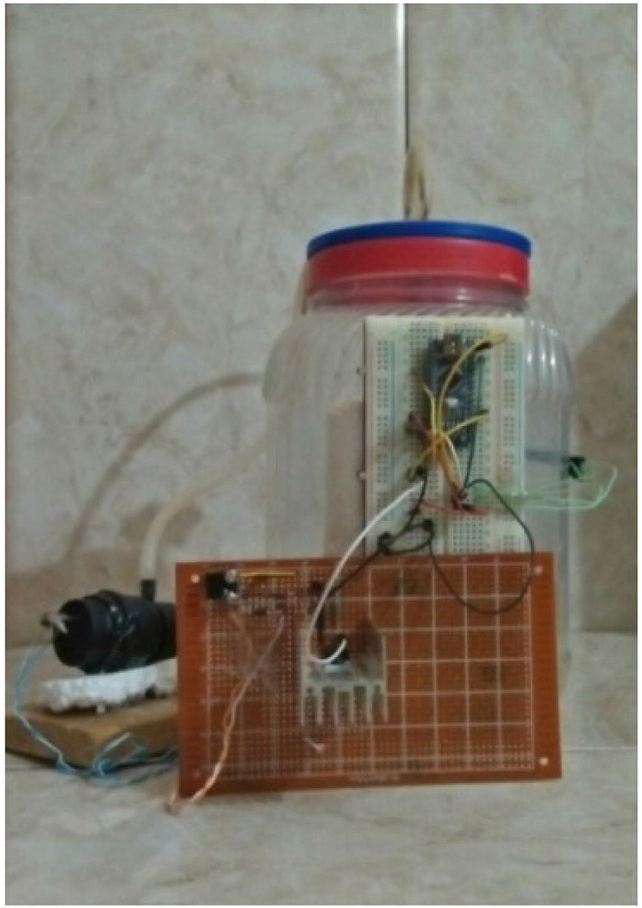

(b)

Fig. 19 First model of SSB: a Front view and $\mathbf{b}$ rear view

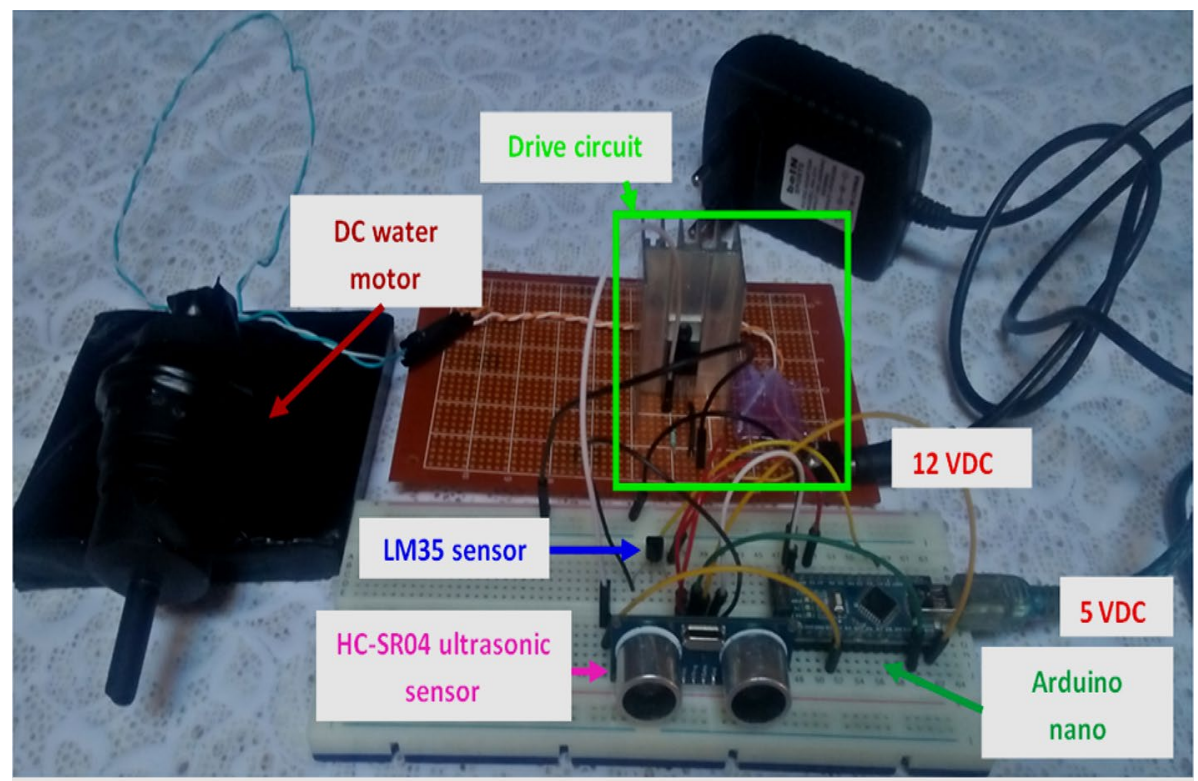

Fig. 20 Essential parts of our prototype 


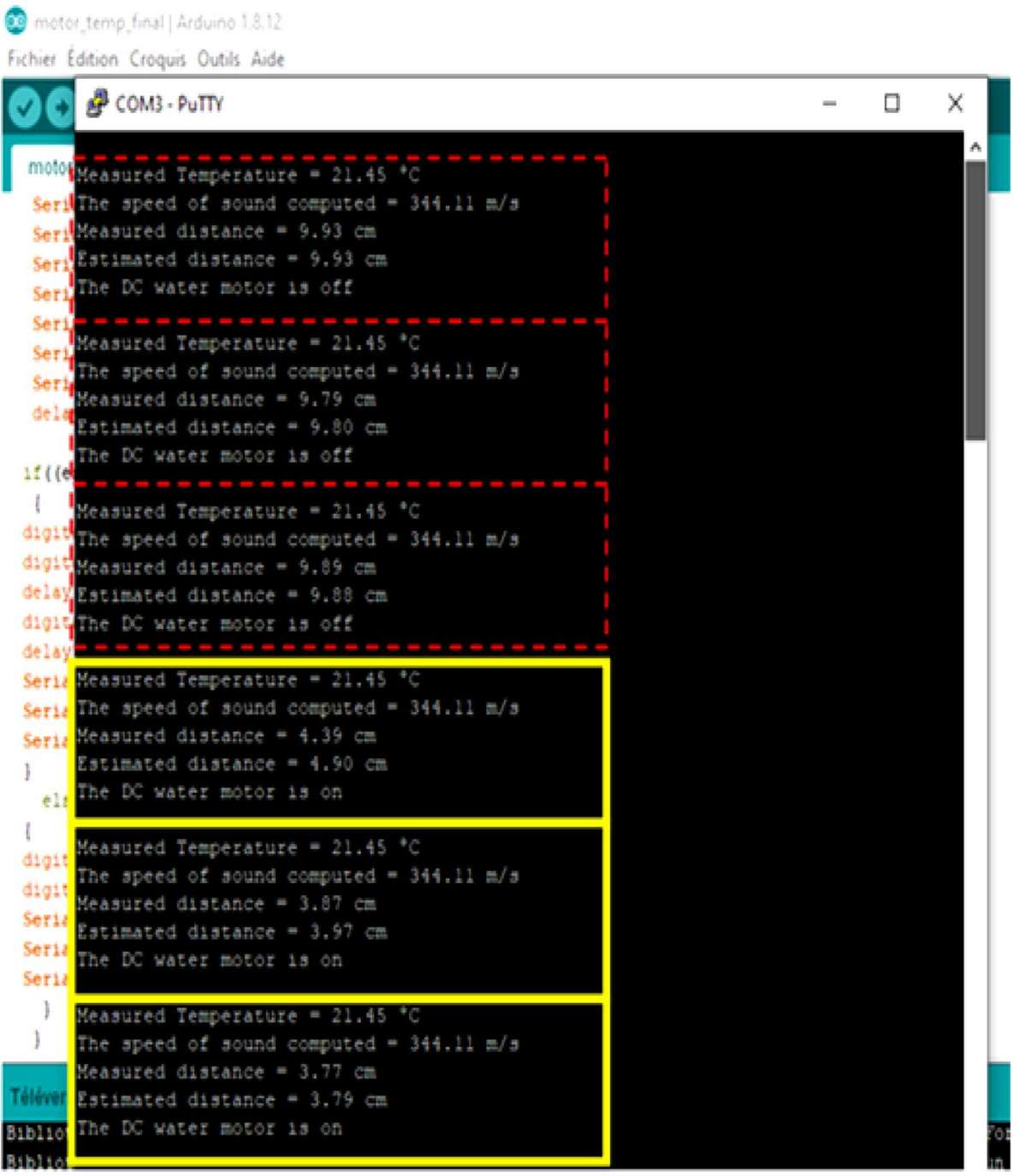

Fig. 21 A few results registered

human hands and the SSB, and the DC water motor status. Concerning the starting of the DC water motor is based on the selection of threshold distance, in our case we chose $5 \mathrm{~cm}$, so when the estimated distance by the KF is less than or equal to $5 \mathrm{~cm}$, the DC water motor is in running condition, otherwise, the $\mathrm{DC}$ water motor is in a stop state for an estimated distance much higher than the threshold distance $5 \mathrm{~cm}$. Table 2 provides the list of hardware components included in Fig. 3 with the total cost of proposed prototype. 


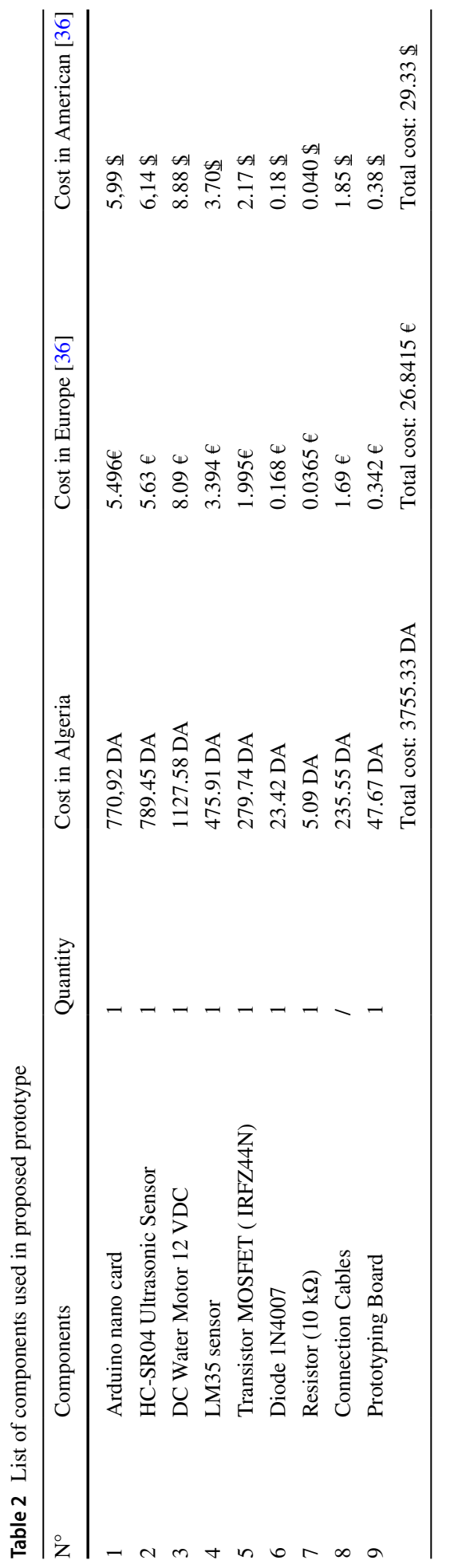




\section{Conclusion}

In light of these circumstances that have affected the whole world, the scientific acceleration in all fields has become very exciting, as all scientists are scrambling to invent a vaccine for the coronavirus and some of them are implicated in inventions that help to limit the spread of this virus, such as the use of drugs or the antiseptic gel for cleaning out the human hands. In this context, we thought of a prototype suggesting a SSB based on a hybrid system employing the LM35 sensor and the HC-SR04 ultrasonic sensor as basic devices, and this for a good sterilization of the human hands against the coronavirus (Covid-19).

However, the employed sensors in our prototype are influenced by the measurement noise, and as a result, this type of the noise can cause undesirable effects when the data are measuring. For this reason, the proposed system has been equipped with a filter in order to stabilize the measurements for improving the performance of proposed system. In this work the KF is applying. The simulations of this work did lead us to the following conclusions:

- the prediction of the speed of sound waves by means of the LM35 sensor did give us reasonable results for measuring a desired distance after the linear interpolation method is applied.

- the KF can stabilize the measured distances after the measurement noise is reduced.

- after the use of the KF estimator, the response time of a HC-SR04 ultrasonic sensor for estimating the measured distance, is acceptable. As an example, with the covariance value of process noise is equal $10^{-1}$, the response time is $4.56 \mathrm{~s}$.

For future endeavors and as a perspective, we will aim to improve the response time for estimating the measured distance with other estimation techniques.

\section{Future work}

In future work, we propose a new prototype with low-cost, which is illustrated in appendix 3 section. In addition, we provide the list of all hardware components in Table 3 (see the Appendix 3 section). However, the cheap prototype circuit based on the FC-51 IR proximity sensor, which this sensor is constituted of an infrared diode (transmitter) and a photodiode (receiver), its role is to sense the human hands to be sterilized which are in front of the sterilization bottle.

Depending on the distance of human hands which will be detected in it, the receiver of the FC-51 IR proximity sensor will receive reflected infrared light (emitted by the infrared diode of the FC-51 IR proximity sensor) in order to supply the DC water motor via the control circuit (we use the same control circuit in this paper) and finally, the antiseptic gel will be pumped out through the vacuum tube to the human hands. We note that the threshold distance between the human hands to be sterilized and the FC-51 IR proximity sensor is set using the potentiometer that is available on the sensor.

In terms of revenue, we conclude that the future proposed prototype with a low-cost costs half the cost compared to the proposed prototype in this paper (see Fig. 3) for the three areas, are as follows: Algeria, Europe and America, see the Table 3 in "Appendix 3" section. 


\section{Appendix 1}

The basic source code to run the proposed prototype is shown in Fig. 22. However, the source code is just as simple, it is programmed in IDE (or integrated development environment) Arduino [37, 38].

\section{Appendix 2}

The LM35 temperature sensor is fairly easy to use. To connect it, we take the VCC pin of the LM35 sensor and fix it to the Arduino nano $5 \mathrm{~V}$ pin. We then take the GND pin of the LM35 sensor and connect it to the Arduino nano GND pin. Finally, the Vout pin of the LM35 sensor is connected to the A0 pin of the arduino nano (see Fig. 23).

According to Fig. 24. the HC-SR04 ultrasonic sensor is fairly simple to employ. To connect it, we take the VCC pin of the sensor and fix it to the Arduino nano $5 \mathrm{~V}$ pin. We then take the GND pin of the sensor and connect it to the Arduino nano GND pin. In addition, the Trig pin of the sensor is connected to pin 10 of the Arduino nano and finally the Echo pin of the sensor which we connect to pin 12 of the Arduino nano.

Figure 25 shows the circuit design of hybrid system for the proposed prototype.

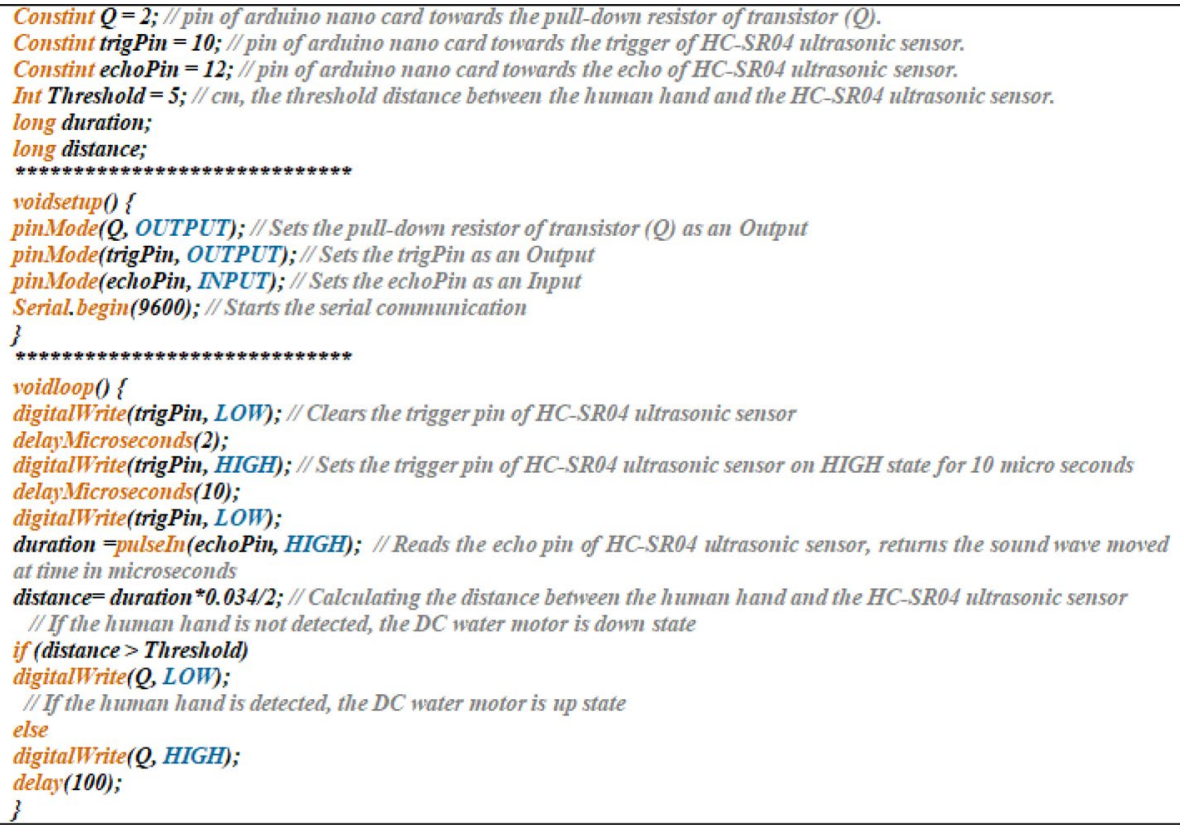

Fig. 22 Basic source code used for the proposed prototype 
Fig. 23 Arduino nano and LM35 sensor connection

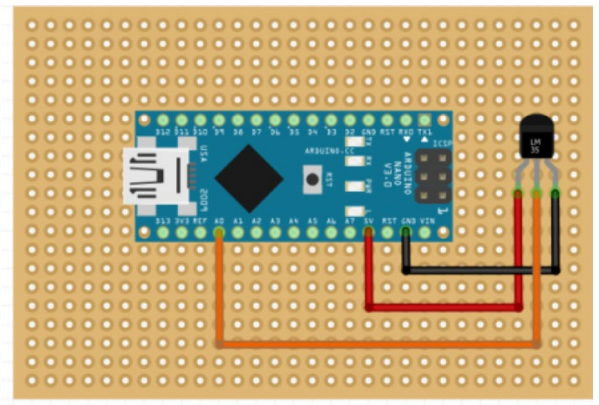

\section{fritzing}

Fig. 24 Arduino nano and HC-SR04 ultrasonic sensor connection

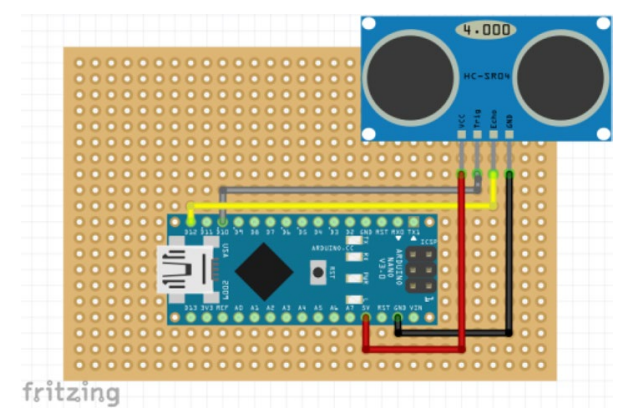

Fig. 25 Proposed Hybrid system for our prototype

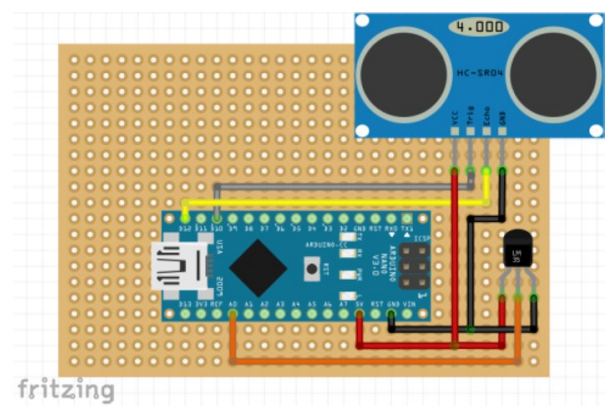

\section{Appendix 3}

Figure 26 shows the proposed future low-cost prototype with the list of components used (see Table 3). 


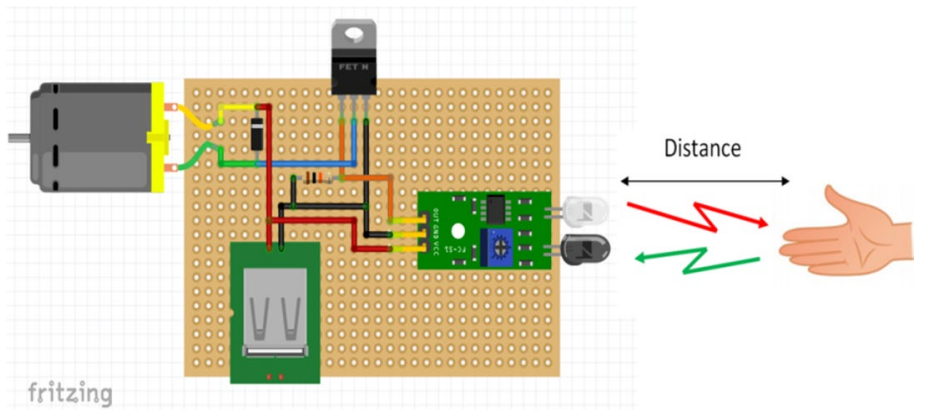

Fig. 26 Future low-cost prototype [39]

Table 3 List of components used in low-cost prototype

\begin{tabular}{|c|c|c|c|c|c|}
\hline No. & Components & Quantity & Cost in Algeria & $\begin{array}{l}\text { Cost in Europe } \\
{[36]}\end{array}$ & $\begin{array}{l}\text { Cost in Ameri- } \\
\text { can [36] }\end{array}$ \\
\hline 1 & FC-51 IR Proximity Sensor & 1 & $359.60 \mathrm{DA}$ & $2.58 €$ & $2.83 \Phi$ \\
\hline 2 & DC Water Motor 5 VDC & 1 & 319.70 DA & $\underline{2.28} €$ & $2.49 \$$ \\
\hline 3 & $\begin{array}{l}\text { Transistor MOSFET } \\
\quad(\text { IRFZ44N) }\end{array}$ & 1 & $279.74 \mathrm{DA}$ & $1.995 €$ & $2.17 \$$ \\
\hline 4 & Resistor (10 k $\Omega$ ) & 1 & $5.09 \mathrm{DA}$ & $0.0365 €$ & $0.040 \$$ \\
\hline 5 & USB-A female Port & 1 & $153.18 \mathrm{DA}$ & $1.099 €$ & $1.21 \Phi$ \\
\hline 6 & Diode 1N4007 & 1 & $23.42 \mathrm{DA}$ & $0.168 €$ & $0.18 \$$ \\
\hline 7 & Connection Cables & / & $235.55 \mathrm{DA}$ & $1.69 €$ & $1.85 \$$ \\
\hline \multirow[t]{2}{*}{8} & Prototyping Board & 1 & $47.67 \mathrm{DA}$ & $0.342 €$ & $0.38 \$$ \\
\hline & & & $\begin{array}{l}\text { Total cost: } \\
1423.95 \mathrm{DA}\end{array}$ & $\begin{array}{l}\text { Total cost: } \\
10.1905 €\end{array}$ & $\begin{array}{c}\text { Total cost: } \\
11.15 \$\end{array}$ \\
\hline
\end{tabular}

Acknowledgements The authors would like to thank the dean of faculty of technology, university Abou Bakr Belkaid-Tlemcen, Algeria, for supporting our work in the midst of a coronavirus (Covid-19) pandemic. Also, we thank director of STIC laboratory.

\section{References}

1. https://radiopaedia.org/articles/covid-19-3

2. Nathalie, K., \& Astrid, V. (2016). Les infections à coronavirus humains. Revue Francophone des Laboratoires, 2016(487), 25-33. https://doi.org/10.1016/S1773-035X(16)30369-0.

3. Rajgor, D. D., Lee, M. H., Archuleta, S., Bagdasarian, N., \& Quek, S. C. (2020). The many estimates of the COVID-19 case fatality rate. The Lancet Infectious Diseases, 20(7), 776-777. https://doi.org/10. 1016/S1473-3099(20)30244-9.

4. Wang, C., Horby, P. W., Hayden, F. G., \& Gao, G. F. (2020). A novel coronavirus outbreak of global health concern. Lancet, 395(10223), 470-473. https://doi.org/10.1016/S0140-6736(20)30185-9.

5. Zhou, X., Shu, L., Shen, T., Hao, L., \& Ling-quan, K. (2020). Full spectrum of COVID-19 severity still being depicted. Lancet, 395(10228), 947-948. https://doi.org/10.1016/S0140-6736(20)30308-1.

6. Rothan, H. A., \& Byrareddy, S. N. (2020). The epidemiology and pathogenesis of coronavirus disease (COVID-19) outbreak. Journal of Autoimmune. https://doi.org/10.1016/j.jaut.2020.102433.

7. Gautret, P., Lagier, J. C., Parola, P., Hoang, V. T., Meddeb, L., Mailhe, M., Doudier, B., Courjon, J., Giordanengo, V., Vieira, V. E., Tissot, D. H., Honoré, S., Colson, P., Chabrière, E., La, S. B., Rolain, J. 
M., Brouqui, P., \& Raoult, D. (2020). Hydroxychloroquine and azithromycin as a treatment of COVID19: results of an open-label non-randomized clinical trial. International Journal of Antimicrobial Agents, 56(1), 105949. https://doi.org/10.1016/j.ijantimicag.2020.105949.

8. Chai, T., \& William, W. (2020). The smart city and Covid-19. IET Smart Cities. https://doi.org/10. 1049/iet-smc.2020.0024.

9. Reybrouck, G. (1981). Sterilization: Comments from Leuven, Belgium. Journal of Hospital Infection, 2, 291-293. https://doi.org/10.1016/0195-6701(81)90060-8.

10. Curtis, V., \& Cairncross, S. (2003). Effect of washing hands with soap on diarrhoea risk in the community: A systematic review. The Lancet Infectious Diseases, 3(5), 275-281. https://doi.org/10.1016/ s1473-3099(03)00606-6.

11. Griffith, C. J., Malik, R., Cooper, R. A., Looker, N., \& Michaels, B. (2003). Environmental surface cleanliness and the potential for contamination during handwashing. American Journal of Infection Control, 31(2), 93-96. https://doi.org/10.1067/mic.2003.62.

12. Jumaa, P. A. (2005). Hand hygiene: simple and complex. International Journal of Infectious Diseases, 9(1), 3-14. https://doi.org/10.1016/j.ijid.2004.05.005.

13. Dale, E., \& Leonard, J. B. (2012). Ultrasonics: Fundamentals, technologies, and applications. (3rd ed.). CRC Press.

14. Jin, S. J., Moon, G. J., Won, C. L., Dong, W. J., \& Zhong, S. L. (2008). Identification and distance detection for ultrasonic sensors by a correlation method. IFAC Proceedings Volumes, 41(2), 75347538. https://doi.org/10.3182/20080706-5-KR-1001.01273.

15. Christian, P., Nicolas, G., \& Primius, B. (2008). Ultrasons et Sonochemie. Techniques de l'ingénieur Intensification des procédés et méthodes d'analyse durable, ref. article : af6310, TIB493DUO. https:// www.techniques-ingenieur.fr/base-documentaire/procedes-chimie-bio-agro-th2/intensification-desprocedes-et-methodes-d-analyse-durable-42493210/ultrasons-et-sonochimie-af6310/.

16. https://www.arduino-france.com/review/arduino-uno/.

17. https://components101.com/ultrasonic-sensor-working-pinout-datasheet.

18. Kalman, R. E. (1960). A new approach to linear filtering and prediction problems. Journal of Basic Engineering, 82, 34-45. https://doi.org/10.1115/1.3662552.

19. Yang, B. H., Yang, W. D., Chen, L. G., \& Qu, L. (2008). Dynamic optimization of feedforward automatic gauge control based on extended Kalman filter. Journal of Iron and Steel Research International, 15(2), 39-42. https://doi.org/10.1016/S1006-706X(08)60028-X.

20. Stéphane, A., Mihai, B. L., Gilles, B., \& Alexandru, S. (2004). Automatic gain control in a Kalman filter based synchronization chaotic receiver. IEEE Communications, 2004, Bucharest, Romania. IEEE.

21. Haitao, Z., \& Yujiao, Z. (2011). The performance comparison and analysis of extended Kalman filters for GPS/DR navigation. Optik International Journal for Light and Electron Optics, 122(9), 777-781. https://doi.org/10.1016/j.ijleo.2010.05.023.

22. Rajat, A. (2013). Doppler utilised Kalman estimation (DUKE) of ionospheric delay for satellite navigation. Advances in Space Research, 51(11), 2171-2180. https://doi.org/10.1016/j.asr.2012.12.022.

23. Gerasimos, G.-R. (2012). Nonlinear Kalman filters and particle filters for integrated navigation of unmanned aerial vehicles. Robotics and Autonomous Systems, 60(7), 978-995. https://doi.org/10. 1016/j.robot.2012.03.001.

24. Muhammad, L. A., Jaehong, P., Wonsang, H., Hyun-il, K., Jong, H. K., Changhun, L., Kwang, S. K., \& Dong-il, D-C. (2010). Sensor data fusion using unscented Kalman filter for accurate localization of mobile robots. In Proceedings of international conference on control, automation and systems (pp. 947-952). IEEE. https://doi.org/10.1109/ICCAS.2010.5669779.

25. Sun, S. L., \& Deng, Z. L. (2004). Multi-sensor optimal information fusion Kalman filter. Automatica, 40(6), 1017-1023. https://doi.org/10.1016/j.automatica.2004.01.014.

26. Michael, P., \& Phillip, A. L. (2003). Kalman filter recipes for real-time image processing. Real-Time Imaging, 9(6), 433-439. https://doi.org/10.1016/j.rti.2003.09.005.

27. Adardour, H. E., Meliani, M., \& Hachemi, M. H. (2015). Estimation of the spectrum sensing for the cognitive radios: Test analysing using Kalman filter. Wireless Personal Communications, 84(2), 15351549. https://doi.org/10.1007/s11277-015-2701-y.

28. Adardour, H. E., \& Kameche, S. (2019). Enhancing the performance of spectrum mobility in cognitive radio local area networks using KF-ABF-SRE estimators. Wireless Personal Communications, 104(4), 1321-1341. https://doi.org/10.1007/s11277-018-6085-7.

29. Adardour, H. E., Hadjila, M., Irid, S. M. H., et al. (2021). Outdoor Alzheimer's patients tracking using an IoT system and a Kalman Filter estimator. Wireless Personal Communications, 116(4), 249-265. https://doi.org/10.1007/s11277-020-07713-4. 
30. Harkat, S. (2016). Application du Filtre de Kalman sur la variabilité pluviométrique dans le bassin versant de Chellif. Thèse de doctorat, Université de Chlef, Algerie. http://dspace.univ-chlef.dz:8080/jspui/ handle/123456789/306.

31. Ole, B., Xinwei, W., Nils, H., Rainer, L., \& Steffen, P. (2010). Implementation of an ultrasonic distance measuring system with Kalman filtering in wireless sensor networks for transport logistics. Procedia Engineering, 5, 196-199. https://doi.org/10.1016/j.proeng.2010.09.081.

32. Adnan, R. Al-T. (2018). Kalman Filter algorithm design for HC-SR04 ultrasonic sensor data acquisition system. IJITEE. https://doi.org/10.22146/ijitee.36646.

33. Meriem, B., \& Ikram, B. (2019). Conception et réalisation d'un système d'acquisition de données d'un capteur ultrasons HC-SR04 en utilisant un algorithme de filtre de Kalman. Mémoire de projet de fin d'études, Université de Tlemcen, Algerie.

34. http://tpe-ondesonore.e-monsite.com.

35. Irid, S.M.H. Hadjila, M. Adardour, H.E. (2019). Design and implementation of an IoT prototype for the detection of carbon monoxide. In 2019 6th international conference on image and signal processing and their applications (ISPA), Mostaganem, Algeria (pp. 1-5). https://doi.org/10.1109/ISPA48434. 2019.8966882.

36. https://www.amazon.com/.

37. https://www.arduino.cc/en/main/software.

38. Irid S. M. H., Hadjila M., Adardour H. E., \& Nouali I. Y. (2021) Design and realization of an IoT prototype for location remote monitoring via a web application. In Ben Ahmed, M., Rakıp Karaș, İ., Santos, D., Sergeyeva, O., \& Boudhir, A. A. (eds.), Innovations in smart cities applications volume 4. SCA 2020. Lecture notes in networks and systems, vol. 183. Springer, Cham. https://doi.org/10.1007/ 978-3-030-66840-2_74.

39. https://artofcircuits.com/product/infrared-obstacle-avoidance-proximity-sensors-module-fc-51.

Publisher's Note Springer Nature remains neutral with regard to jurisdictional claims in published maps and institutional affiliations.

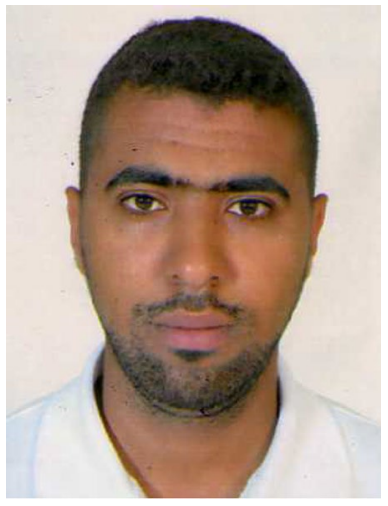

H. E. Adardour was born in Maghnia, Algeria in 1988. He is a Ph.D. degree in Telecommunications at the faculty of technology, University of Tlemcen-Algeria, in 2016. He is a member of STIC laboratory in the same university. After receiving his Master degree in components and electronics systems for telecommunications from the university of Tlemcen, in 2012. Since 2019, he is lecturer of systems and communications engineering at the university of Hassiba Benbouali Chlef, Algeria. His current research focuses on wireless communications, cognitive radio networks, spectrum sensing, free space optical networks and the concept of the Internet of things. 

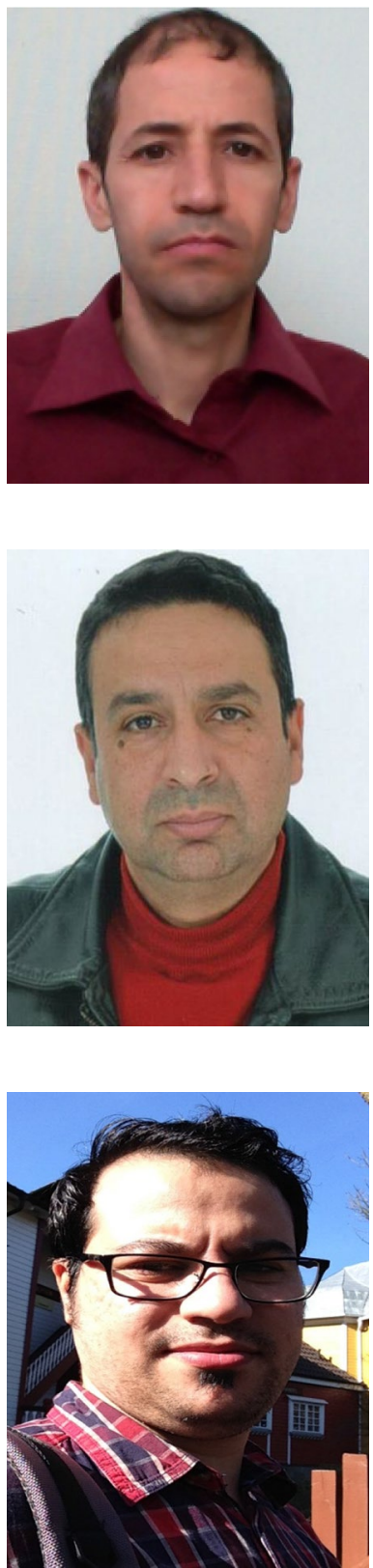

M. Hadjila received his engineer degrees in 1994, his M.S. degrees in signals and systems in 1999, and his Ph.D. in Telecommunications in 2014 from the University of Tlemcen, Algeria. Since 2019, he is lecturer of Telecommunication Engineering at university of Tlemcen. Member of STIC laboratory in the same University. His research interest is in telecommunication systems, mobile networks, Internet of Things and Big Data.

S. M. H. Irid received Engineer and Magister degrees in electronic and communication engineering from Tlemcen university, Algeria, in 1996 and 2000 respectively. Then he studied digital communication in Valenciennes University, France in 2001. He has been a network supervisor at IBM Montreal, Canada, then a project manager at Orascom Telecom Algeria. Since 2008, he is lecturer at university of Tlemcen. His research interests are in the area of digital communication and array signal processing.

M. H. Hachemi received his Engineer degree in Telecommunication from the University of Saiida-ALGERIA in 2007, the subject studied: Studies and Realization Detection of a Gas Leak by SMS and this project was ranked among the 16 inventions in the Arab world by the emission "Stars of Science" in Tunisia. From 2008 to 2011 he receives the formation of Magister in the doctoral school entitled "Science, Information Technology and Telecommunications" from Faculty of Engineering Djillali Liabes University, Sidi Bel Abbes, ALGERIA. From 2012, he integrated as a member and Ph.D. student of STIC laboratory in the University of Tlemcen, his research interests: NEMO communications, Mobile networks and Wireless Communications. 

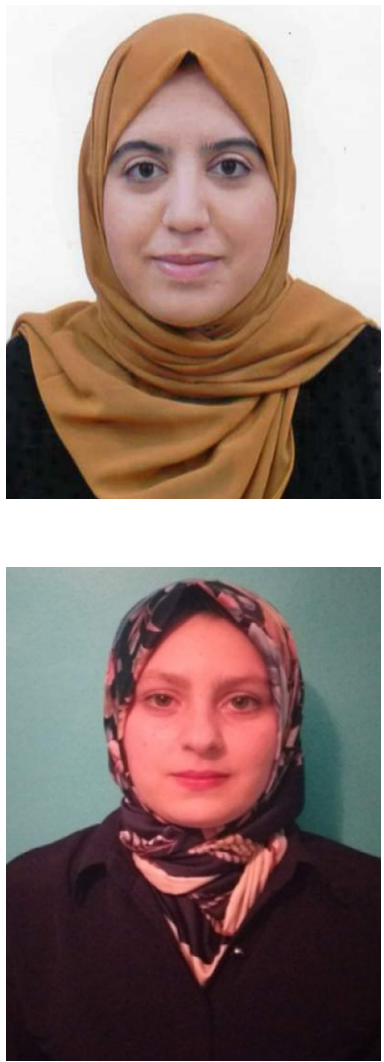

M. Benikhlef received his masters degree in Telecommunications at the University of Tlemcen, Algeria, in 2019. His current research focuses on wireless communications and the concept of the internet of things, in the same University.

I. Benotmane received his masters degree in Telecommunications at the University of Tlemcen, Algeria, in 2019. His current research focuses on wireless communications and the concept of the internet of things, in the same University. 